\title{
DNA-Scaffolded Proximity Assembly and Confinement of Multienzyme Reactions
}

\author{
Jinglin $\mathrm{Fu}^{1,2}$ (D) Zhicheng Wang ${ }^{1,2} \cdot$ Xiao Hua Liang ${ }^{1} \cdot$ Sung Won $\mathrm{Oh}^{2}$. \\ Ezry St. lago-McRae ${ }^{2}$. Ting Zhang ${ }^{1}$
}

Received: 21 October 2019 / Accepted: 7 March 2020 / Published online: 4 April 2020

(c) Springer Nature Switzerland AG 2020

\begin{abstract}
Cellular functions rely on a series of organized and regulated multienzyme cascade reactions. The catalytic efficiencies of these cascades depend on the precise spatial organization of the constituent enzymes, which is optimized to facilitate substrate transport and regulate activities. Mimicry of this organization in a non-living, artificial system would be very useful in a broad range of applications-with impacts on both the scientific community and society at large. Self-assembled DNA nanostructures are promising applications to organize biomolecular components into prescribed, multidimensional patterns. In this review, we focus on recent progress in the field of DNA-scaffolded assembly and confinement of multienzyme reactions. DNA self-assembly is exploited to build spatially organized multienzyme cascades with control over their relative distance, substrate diffusion paths, compartmentalization and activity actuation. The combination of addressable DNA assembly and multienzyme cascades can deliver breakthroughs toward the engineering of novel synthetic and biomimetic reactors.
\end{abstract}

Keywords Biomimetic systems $\cdot$ DNA nanotechnology $\cdot$ DNA scaffolded assembly · Enzyme encapsulation · Enzyme immobilization · Enzyme regulation · Multienzyme cascade $\cdot$ Synthetic reactors

\section{Abbreviations \\ BG Benzylguanine \\ BQ Benzoquinone}

This article is part of the Topical Collection "DNA Nanotechnology: From Structure to Functionality"; edited by Chunhai Fan, Yonggang Ke.

Jinglin Fu

jinglin.fu@ rutgers.edu

1 Department of Chemistry, Rutgers University-Camden, Camden, NJ 08102, USA

2 Center for Computational and Integrative Biology, Rutgers University-Camden, Camden, NJ 08102, USA 


$\begin{array}{ll}\text { CH } & \text { Chlorohexane } \\ \text { DSS } & \text { Disuccinimidyl suberate } \\ \text { DTPC } & \text { DNA-templated protein conjugation } \\ \text { DX } & \text { Double-crossover DNA tile } \\ \text { G6PDH } & \text { Glucose-6-phosphate dehydrogenase } \\ \text { GOx } & \text { Glucose oxidase } \\ \text { HRP } & \text { Horseradish peroxidase } \\ \text { IDE } & \text { Inhibitor-DNA-enzyme } \\ \text { LDH } & \text { Lactate dehydrogenase } \\ \text { MDH } & \text { Malic dehydrogenase } \\ \text { MTG } & \text { Microbial transglutaminase } \\ \text { NHS } & \text { N-hydroxysuccinimide } \\ \text { NiR } & \text { Nitrite reductase } \\ \text { ORBIT } & \text { Origami-rotor-based imaging and tracking } \\ \text { Paz } & \text { Pseudoazurin } \\ \text { Pg } & \text { Plasminogen } \\ \text { PLP } & \text { Pyridoxal 5'-phosphate } \\ \text { SK } & \text { Streptokinase } \\ \text { SMCC } & \text { Succinimidyl-4-(N-maleimidomethyl) cyclohexane-1-carboxylate } \\ \text { SPDP } & \text { Succinimidyl 3-(2-pyridyldithio) propionate } \\ \text { STVs } & \text { Streptavidins } \\ \text { TAL } & \text { Transcription activator-like } \\ & \end{array}$

\section{Introduction}

Multistep enzyme pathways play critical roles in cellular metabolism that produces biomolecules and harvests energy for sustaining and propagating living systems. As of 2019, 7727 different enzymes have been recorded in the BRENDA database, a comprehensive enzyme information system, including enzymes found in human cells and bacteria. These enzymes catalyze more than 5000 different biochemical reactions in the human body [1]. Enzyme cascades are highly sophisticated systems that control and regulate thousands of chemical reactions in cells. Peter Roach described chaos reactions with a set of spatio-temporally disorganized enzymes as a symphony without a conductor [2] (Fig. 1a). Enzyme cascades, therefore, can behave as a conductor of a symphony, controlling and guiding biochemical reactions into productive and coordinated pathways. The functions of many pathways critically depend on the relative position, orientation and number of participating enzymes [3,4]. Living things have evolved several strategies to organize and confine multienzyme reactions. One such strategy is a protein scaffold, such as the long, glycoprotein "scaffold" used by cellulosomes to selectively integrate various cellulases and xylanases into a proximity complex for the efficient binding and degradation of cellulose [5] (Fig. 1b). Another example is substrate channeling; as shown in Fig. 1c, an indole tunnel observed in a tryptophan synthase $\alpha_{2} \beta_{2}$ complex passes indole intermediates between active sites of the alpha subunit and beta subunit at a very rapid rate of $1000 \mathrm{~s}^{-1}$ or faster [6]. A third biological strategy, 

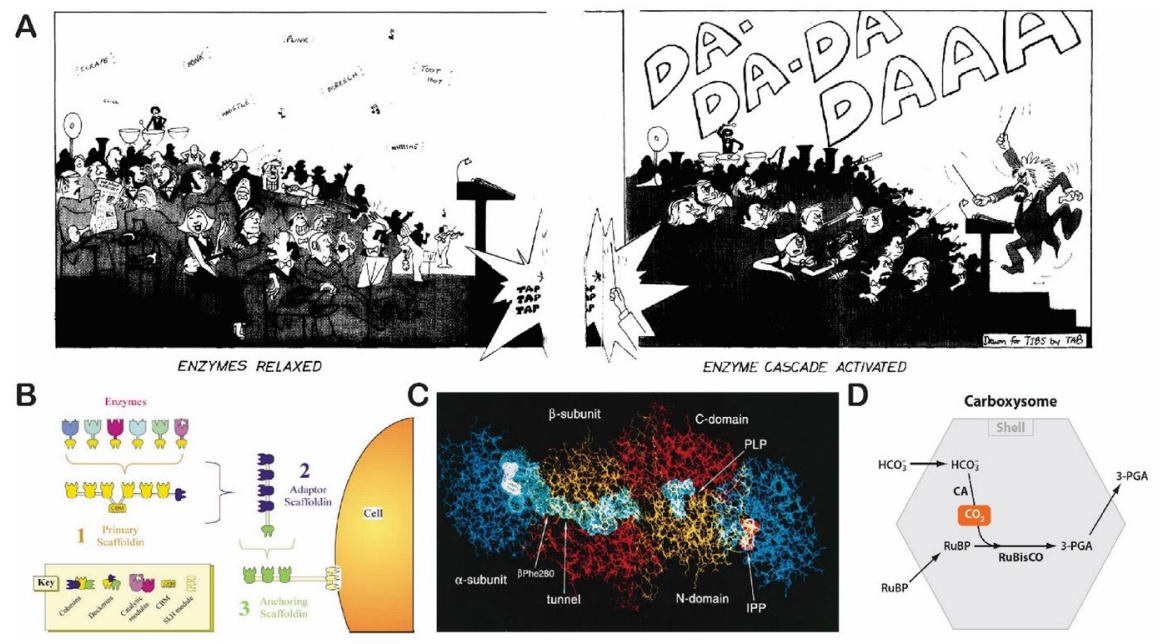

Fig. 1 Cellular multienzyme cascade pathways. a A cartoon of symphony performance to describe the integrated and regulatory function of enzyme cascades. Reproduced from Roach [2], with permission, copyright 1977, Trends in Biochemical Sciences. b The proximity assembly of enzymes on a protein scaffold in a cellulosome. Reproduced from Bayor et al. [5], with permission, copyright 2004, Annual Review of Microbiology. c Substrate channeling in tryptophan synthase. Reproduced from Miles et al. [6], with permission, copyright 1999, American Society for Biochemistry and Molecular Biology. d Confined carbon dioxide $\left(\mathrm{CO}_{2}\right)$ fixation in a carboxysome. Reproduced from Yeates et al. [7], with permission, copyright 2010, Annual Review of Biophysics

compartmentalization, shown in Fig. 1d, is used by bacterial carboxysomes to carry out carbon dioxide $\left(\mathrm{CO}_{2}\right)$ fixation [7].

The ability to exert control over these biochemical pathways on the nanoscale will not only increase our understanding of cellular metabolism, but also provide innovative tools to mimic and translate cellular mechanisms into non-living artificial systems for novel applications. Recent decades have seen the development of various approaches to create artificial multienzyme complexes, including genetic fusion [8], chemical crosslinking [9], surface co-immobilization [10], polymer vesicles [11-13] and virus-like particles $[14,15]$. However, several obstacles remain in terms of their broader applications, such as limited control over the spatial arrangement (sizes and shapes), low encapsulation yield of large proteins due to steric hindrance, insufficient access of substrates to enzyme assemblies and aggregation of vesicle shells. It also remains challenging to engineer biomimetic functions on nanoreactors, such as artificial nanopores that govern the transmembrane diffusion of molecules and the feedback regulation of enzyme functions.

Double-stranded DNA (dsDNA) is a self-assembling biopolymer that is directed by Watson-Crick base pairing. Ned Seeman first proposed and demonstrated that artificially branched DNA tiles could be assembled by rationally designed singlestranded DNA (ssDNA) [16]. Such structures can have complex shapes beyond those attained by biological evolution and can be designed using "simple" elements, such as the "Holliday" junction (Fig. 2a) and double-crossover (DX) tiles (Fig. 2b) [16-19]. Two key breakthroughs in structural DNA nanotechnology are 
Fig. 2 Overview of structural DNA nanotechnology. a A four-way "Holliday" junction. Reproduced from Seeman [19], with permission, copyright 2003, Springer Nature. b DNA double-crossover (left) and triple-crossover (right) tiles. Reproduced from Zadegan and Norton [18], with permission, copyright 2012, MDPI. c DNA origami assembly. Reproduced from Rothemund [20], with permission, copyright 2006, Springer Nature. d Assembly of single-stranded DNA tiles. Reproduced from Wei et al. [21], with permission, copyright 2012, Springer Nature. e DNA scaffold-directed assembly of biomolecular complexes. Reproduced from Fu et al. [36], with permission, copyright 2019, John Wiley and Sons

scaffolded DNA origami, invented by Paul Rothemund in 2006 (Fig. 2b) [20], and ssDNA tiles (SST), reported by Peng Yin in 2012 (Fig. 2c) [21, 22]. These methods have empowered the design and fabrication of complex and multidimensional nanostructures, including one-dimensional (1D) nanotubes, two-dimensional (2D) rectangular or triangular shapes [20], curved containers [23, 24], nanoscale polyhedrons [25], polyhedral meshes [26, 27] and periodic DNA crystals [28, 29]. Recent progress has been made to scale up DNA assemblies in terms of size and quantity [30] and to fold nanostructures with single-stranded nucleic acids [31]. To facilitate the design of DNA nanostructures, several computational tools, including TIAMAT [32], NUPACK [33], caDNAno [34] and CanDo [35], have been developed that benefit researchers worldwidely.

DNA nanostructures are promising assembly scaffolds for positioning other elements into diverse patterns at the nanoscale [36, 37]. As shown in Fig. 2d, DNA scaffold-directed assembly has the advantages of programmable and prescribed geometry, sequence-addressable assembly and adaptability to various bioconjugations [36]. Utilizing these unique features, Researchers have used DNA nanostructures to assemble complex biomolecular systems, such as multienzyme complexes, protein confinement and biomimetic channeling $[37,38]$. They have also been used to guide the assembly of synthetic vesicles, including membrane confinement [39, $40]$ and transmembrane nanopores [41, 42].

In this review, we summarize and discuss the recent progress in the field of DNA scaffold-directed assembly of multienzyme reactions, including proximity assembly, confinement, biomimetic substrate channeling and regulation circuits, as well as bioconjugation techniques of hybrid DNA-protein structures.

\section{Protein-DNA Bioconjugation}

A variety of chemical methods have been developed to attach proteins to DNA nanostructures [37, 43]. Most DNA-protein conjugations can fall into one of three categories: covalent crosslinking, noncovalent binding and fusion tags (summarized in Table 1). Covalent crosslinking usually involves conjugation of an existing amino acid group (e.g. primary amine or thiol) on the protein surface to a chemically modified oligonucleotide. For example, succinimidyl-4-( $N$-maleimidomethyl) cyclohexane-1-carboxylate (SMCC) and succinimidyl 3-(2-pyridyldithio) propionate (SPDP) are two widely used crosslinkers that conjugate a primary amine from a lysine residue on an enzyme surface to a thiol-modified oligonucleotide [44, 45]. The difference between the two crosslinkers is that the disulfide linkage of SPDP is 
A

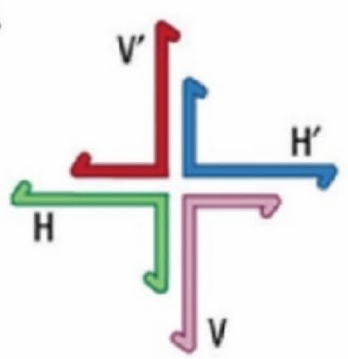

B

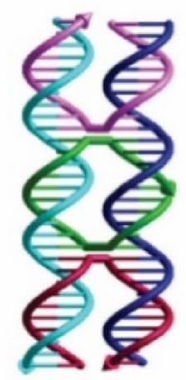

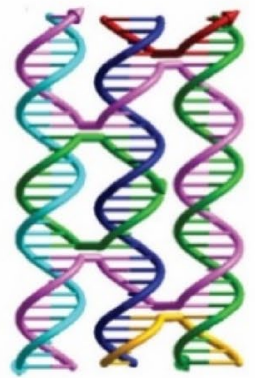

"Holliday" junction

Double (left) and Triple (right) crossovers

C
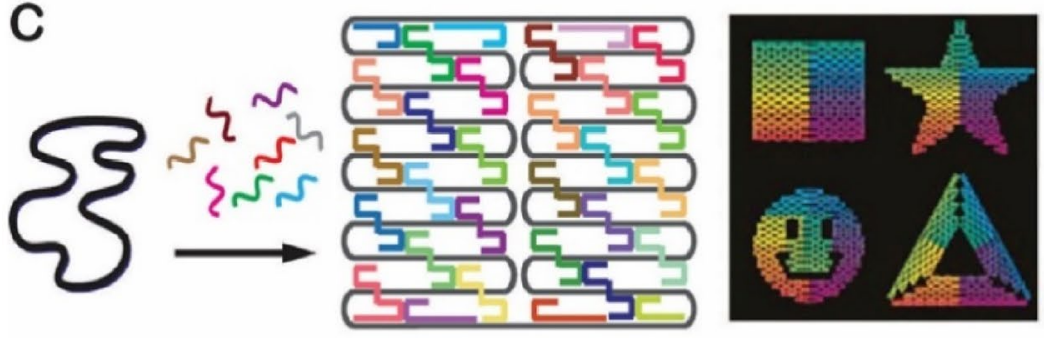

D
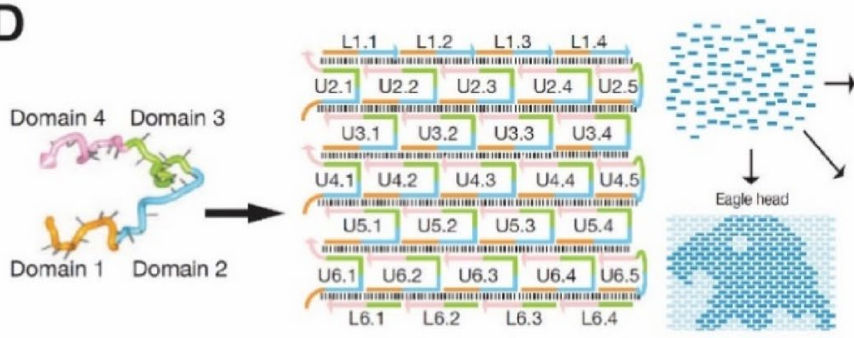

Molecular canvas Molecular canvas
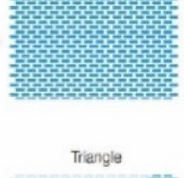

Domain 1 Domain 2

E

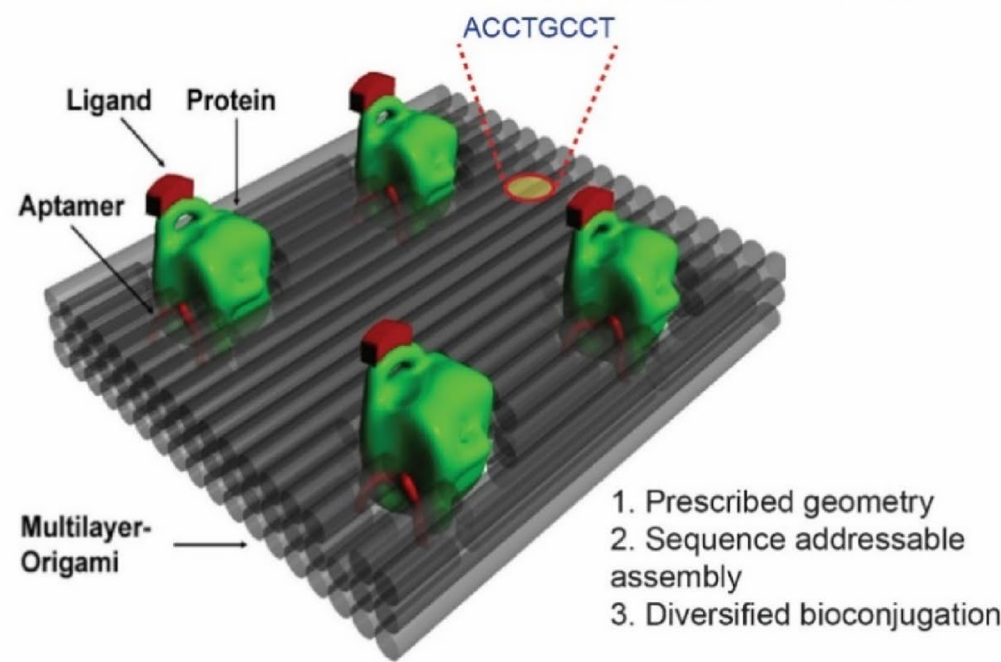




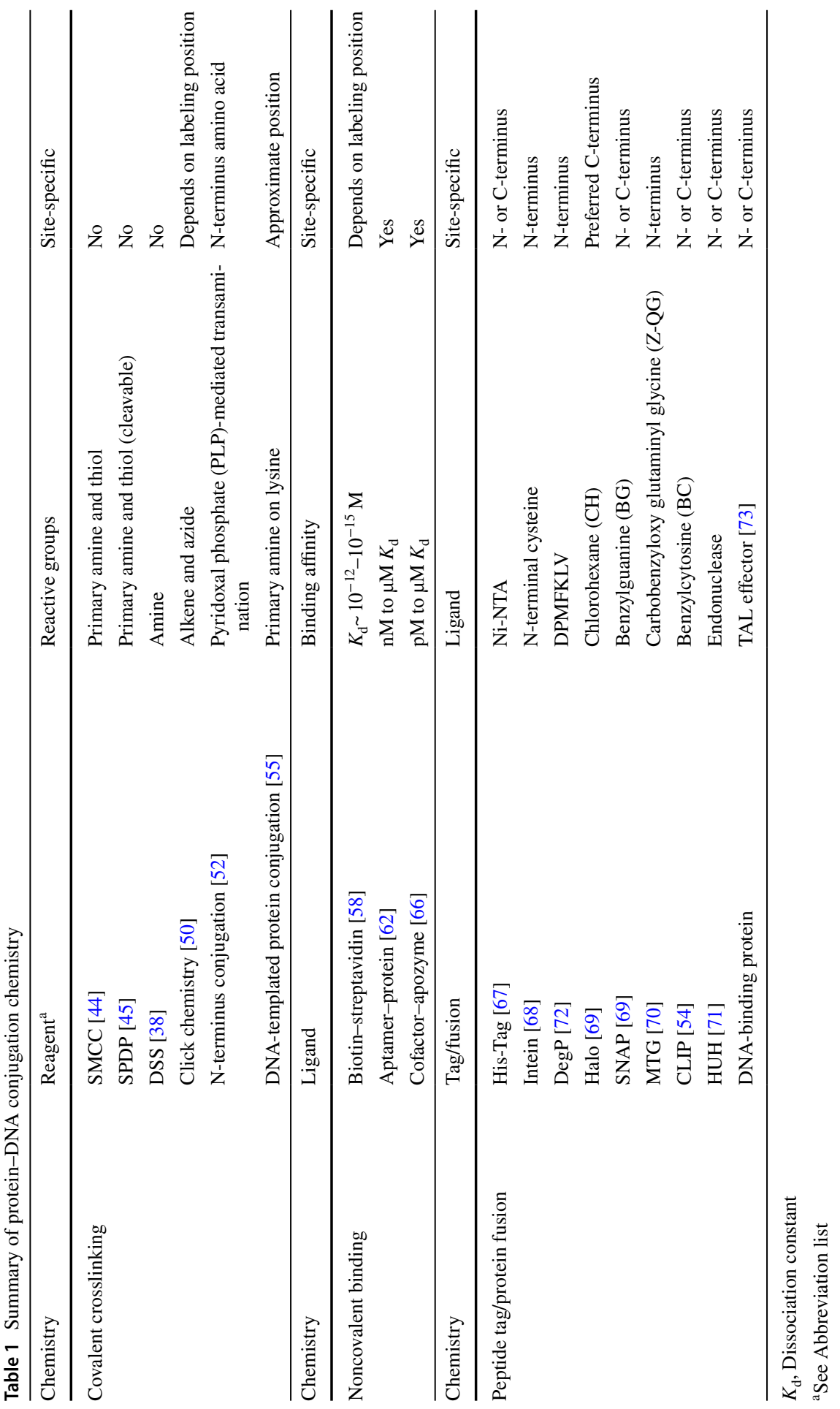


cleavable upon the addition of a reducing reagent, such as T-CEP or mercaptoethanol, while the linkage of SMCC is not cleavable. SMCC and SPDP crosslinkers are generally not site-specific in their reaction with lysines due to the presence of multiple lysine residues on the protein surface. The product of such non-specific conjugation is a heterogeneous mixture of DNA-tagged proteins. In some studies, SMCC or SPDP was used to conjugate a cysteine residue of a protein with an amine-modified DNA strand. This could be site-specific if there were only one cysteine displayed on the protein surface, such as cytochrome $c$ [46]. Another commonly used crosslinker is disuccinimidyl suberate (DSS) in which the double succinimide ends can react with two primary amines to link them together [47]. DSS is especially useful for conjugating amine-modified ssDNA with organic cofactors, such as NAD or ATP [47-49].

Considerable progress has been made over the past two decades to improve the site-specificity of DNA-protein crosslinking. Click reactions (such as copper-catalyzed, azide-alkyne cycloaddition) combined with non-natural amino acid incorporation can produce easily purified conjugates with high site-specificity and yield [50]. To reduce the toxic damage of copper ions, Khatwani et al. used a copperfree click reaction (e.g. strain-promoted [3+2] azide-alkyne cycloaddition) to produce protein-DNA conjugates [51]. Francis and coworkers reported a protein bioconjugation at an N-terminal amino acid via a pyridoxal 5'-phosphate (PLP)mediated transamination reaction [52], and Takeda et al. reported the development of a method to chemically modify an oligonucleotide to a N-terminal cysteine of a protein [53]. Proximity ligation has also been applied to site-specific labeling of an oligonucleotide on a protein by affinity binding-mediated conjugation [54]. Rosen et al. developed a DNA-templated protein conjugation (DTPC) technique to create site-selective DNA-protein conjugation [55]. In the DTPC technique, a guiding DNA strand first co-locates with a metal-binding site of a protein, followed by the introduction of a second DNA strand that conjugates to the lysine residues in the vicinity of the metal-binding site. For a more detailed discussion of site-selective conjugation of native proteins with DNA, the reader is referred to a recent review by Trads et al. [56].

Noncovalent binding may also be used to link DNA with proteins. The classic example is that of the strong binding of biotin to streptavidin [dissociation constant $\left(K_{\mathrm{d}}\right)<10^{-12} \mathrm{M}$ ] to attach a biotinylated DNA to a streptavidin [57] or streptavidintagged enzymes [58]. With the development of oligonucleotide aptamers, aptamerdirected assembly has been adapted to immobilize proteins onto DNA nanostructures by site-specifically incorporating aptamer sequences into DNA nanostructures. This approach has been demonstrated to effectively anchor multiple protein targets onto rationally-designed DNA nanoscaffolds, including thrombin [59], plateletderived growth factor [60] and cell-cell interactions [61]. More importantly, DNA nanostructures can be used to organize multivalent aptamers with optimized spacing distances to enhance their binding affinity [62]. These spatially optimized multivalent aptamers bind to a protein with low nanomolar-or even picomolar- $K_{\mathrm{d}}$, whereas a single aptamer-protein binding is much weaker with several hundred-fold higher $K_{\mathrm{d}}[62,63]$. Similarly, short polypeptide ligands can also be positioned onto the surface of DNA nanostructures for protein binding (e.g. antibody, tumor necrosis 
factor- $\alpha$ and transferrin) $[64,65]$. In addition to aptamers, reconstituted apoenzymes are used to tightly bind to an organic cofactor-modified oligonucleotide [66].

Genetically modified proteins with a short peptide tag or a fusion tag offer more control over the site-specificity of any DNA-protein conjugation. Poly(histidine) ${ }_{6}$ is one widely used peptide tag that can be incorporated into either the $\mathrm{N}$ - or C-terminus of a protein by binding to a nitrilotriacetic acid (NTA)-modified oligonucleotide in the presence of nickel ions [67]. In the last 20 years many techniques have been developed for constructing recombinant (terminus fused) proteins that can bind with ligand-modified nucleic acids. For example, intein-fused proteins can ligate with an N-terminal cysteine-tagged oligonucleotide via the formation of a peptide bond linkage [68]. The research group of Niemeyer and coworkers used "Halo-tag"- and "SNAP-tag"-modified proteins to conjugate with chlorohexane $(\mathrm{CH})$ or benzylguanine (BG)-modified oligonucleotides, respectively [69]. Similar examples of fusionmediated DNA-protein conjugation include a microbial transglutaminase (MTG) fusion [70], a CLIP tagging [54], a HUH tagging [71] and a DegP (serine protease) fusion [72]. Additionally, Dietz and coworkers recently used transcription activator-like (TAL) effector proteins to recognize and bind to specific DNA sequences for creating DNA-protein hybrid nanostructures [73]. These TAL effectors can be genetically introduced into the sequence of other enzymes for anchoring them onto DNA nanostructures.

Following conjugation, the purification of DNA-conjugated proteins is especially important to produce a high-quality sample. The presence of unconjugated DNA or free proteins decreases the assembly yield of proteins onto DNA nanostructures. The most common purification methods include molecular-weight cutoff filtration, gel electrophoresis and chromatography. Due to the negative charge of the DNA phosphate backbone, ion-exchange chromatography is the preferred method to purify DNA-conjugated proteins while separating proteins labeled with different numbers of DNA sidechains. Detailed procedures for purifying DNA-conjugated proteins have been summarized in a recently published protocol [38].

\section{Spatial Organization of Multienzyme Assemblies on DNA Nanostructures}

In cellular metabolism, the function of multienzyme cascades largely depends on their spatial organization, such as the relative distance, orientation, stoichiometry and confinements of the individual protein components [3]. Self-assembled DNA nanostructures are promising scaffolds on which to organize macromolecules because of the spatial addressability of DNA nanostructures [36]. Through various conjugations linking proteins with nucleic acids, DNA nanostructures are capable of controlling multienzyme assemblies in 1D, 2D, and three-dimensional (3D) geometric patterns that can be used to boost catalytic efficiency, improve reaction selectivity and investigate mechanistic kinetics of multienzyme reactions.

Early efforts in this field started with CM Niemeyer's work of aligning enzymes on linear dsDNA scaffolds [58]. As shown in Fig. 3a, a bienzymatic NAD(P)H:FMN oxidoreductase (flavin reductase) and luciferase cascade were assembled together 
A
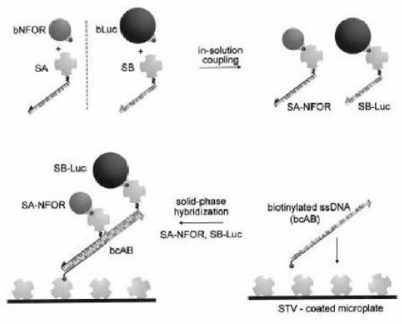

C

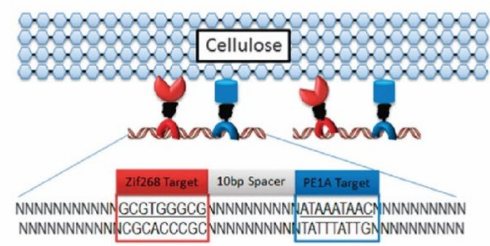

B
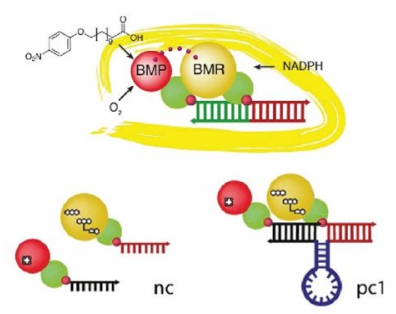

D

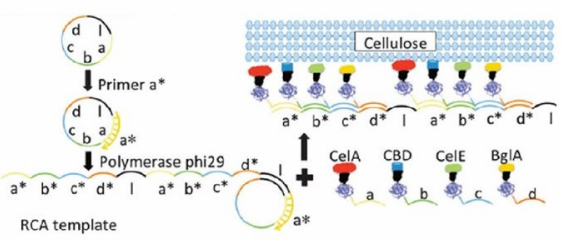

Fig. 3 Assembly of enzyme cascades on linear double-stranded DNA scaffolds. a NAD(P)H:FMN oxidoreductase and luciferase cascade. Reproduced from Niemeyer et al. [58], with permission, copyright 2002, John Wiley and Sons. b Engineered cytochrome P450 BM3 complex varying the distance between the BMR reductase domain and the BMP porphyrin domain. Reproduced from Erkelenz et al. [74], with permission, copyright 2011, American Chemical Society. c Zinc finger protein (ZFP)-appended proteins for cellulose degradation. Reproduced from Sun et al. [76], with permission, copyright 2013, Royal Society of Chemistry. d Rolling circle amplification $(R C A)$ assembly of multienzyme nanowires to promote cellulose degradation. Reproduced from Sun and Chen [77], with permission, copyright 2016, Royal Society of Chemistry

onto a dsDNA scaffold via the strong binding of biotinylated enzymes with DNAstreptavidins [58]. A similar strategy was later used to assemble a cytochrome P450 BM3 enzyme on an adjustable dsDNA scaffold that could vary the distance between the two chimeras of the BMR reductase domain and the BMP porphyrin domain (Fig. 3b) [74]. Linear dsDNA scaffolds have also been used to guide the assembly of artificial cellulosomes composed of multiple cellulases [75-78]. As shown in Fig. 3c, the research group of Chen and coworkers used zinc-finger protein (ZFP) fusion to guide the assembly of two ZFP-appended proteins (an endoglucanase CelA and a cellulose-binding module CBM) into a bifunctional cellulosome structure for enhanced cellulose hydrolysis [76]. Rolling circle amplification (RCA) can produce long ssDNA scaffolds using a circular vector, a primer and a polymerase [77, 79]. As shown in Fig. 3d, these long ssDNA scaffolds produced by RCA can be used to anchor multiple copies of enzyme cascades via specific hybridizations between the section of DNA templates and the anchor DNA on the enzymes [77].

2D and 3D DNA nanostructures offer the ability to design more complex geometric patterns of multienzyme systems. As shown in Fig. 4a, the Wilner research group reported the self-assembly of a two-enzyme cascade array on 2D hexagonal DNA tiles with a controlled distance between enzymes [44]. The assembled glucose oxidase (GOx)-horseradish peroxidase (HRP) cascade showed a more than tenfold activity enhancement compared with unassembled enzymes. To precisely control the spacing distance between enzymes, Fu et al. organized a GOx-HRP pair on a 

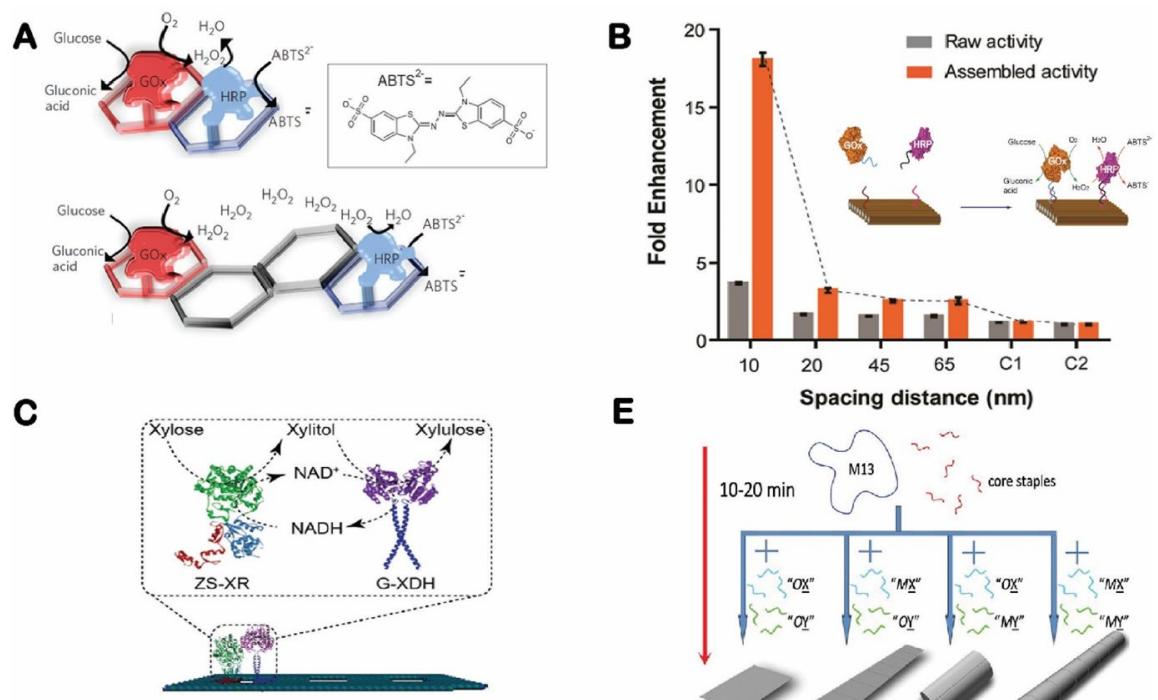

E

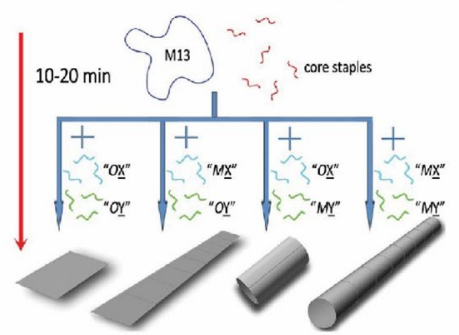

D
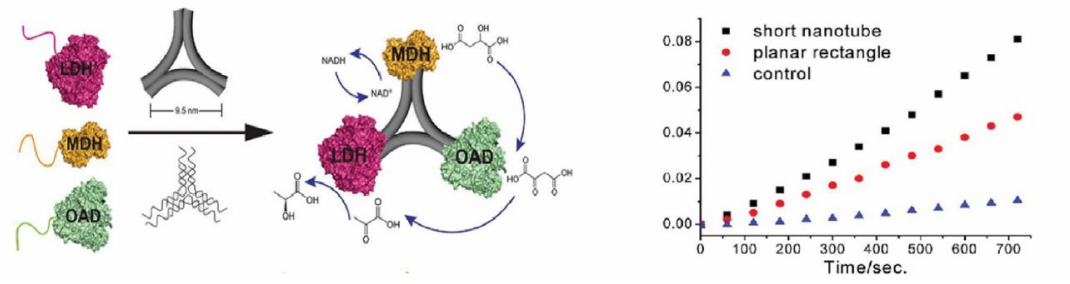

Fig. 4 Enzyme cascades organized on two-dimensional DNA nanostructures. a A glucose oxidasehorseradish peroxidase (GOx/HRP) cascade array on two-dimensional (2D) hexagonal DNA strips. Reproduced from Wilner et al. [44], with permission, copyright 2009, Springer Nature. b Organization of a GOx/HRP cascade on DNA origami tiles with controlled spacing. Reproduced from Fu et al. [45], with permission, copyright 2012, American Chemical Society. c Assembly of an NAD cofactor-coupled enzyme cascade ( $X R$ xylose reductase, $X D H$ xylitol dehydrogenase). Reproduced from Ngo et al. [81], with permission, copyright 2016, American Chemical Society. d A three-enzyme ( $M D H$ malic dehydrogenase, $O A D$ oxaloacetate decarboxylase, $L D H$ lactate dehydrogenase) cascade organized on a triangular DNA origami structure. Reproduced from Liu et al. [83], with permission, copyright 2016, John Wiley and Sons. e A rectangular DNA origami rolling into a DNA nanotube for assembly of an enzyme cascade. Reproduced from Fu et al. [80], with permission, copyright 2013, American Chemical Society

rectangular DNA nanostructure with controlled distances between enzymes that varied from 10 to $65 \mathrm{~nm}$ (Fig. 4b). This spatially organized assembly was used to probe the distance-dependent activity of enzyme cascade reactions and to enhance the mass transport of the $\mathrm{H}_{2} \mathrm{O}_{2}$ intermediate [45]. Similarly, Morii and coworkers reported the assembly of an $\mathrm{NAD}^{+}$cofactor-coupled enzyme cascade of xylose reductase and xylitol dehydrogenase on a 2D DNA origami for carrying out the conversion of xylose into xylulose (Fig. 4c) [81]. The close proximity of two enzymes was found to facilitate the recycling of $\mathrm{NAD}^{+}$to $\mathrm{NADH}$, thereby increasing the xylulose production rate. A subsequent study by the same group extended the assembly 
of a three-enzyme cascade converting xylose to xylulose 5-phosphate with coupled $\mathrm{NAD}^{+}$and ATP cofactors [82]. As shown in Fig. 4d, the research group of Yan and coworkers demonstrated a three-enzyme pathway involving malic dehydrogenase, oxaloacetate decarboxylase and lactate dehydrogenase on a triangular DNA origami [83]. The geometric patterns of these assembled enzyme complexes were found to affect the overall pathway activities by promoting the recycling rate of cofactors in the coupled reactions. Regarding 3D structures, the Fan research group developed a one-pot assembly of DNA nanostructures by rolling a rectangular DNA origami into a DNA nanotube (Fig. 4e) [80]. Using this strategy, enzyme cascade pairs were first anchored onto a rectangular origami, followed by structural rolling to confine enzymes to the exterior of a DNA nanotube, enhancing the cascade's activity.

In addition to DNA, RNA molecules can also be engineered into discrete and multidimensional nanostructures [31, 84]. Because RNA structures can be expressed inside cells, they offer the capability to organize metabolic pathways for in vivo applications. Delebecque et al. designed and assembled multiple shapes of discrete 1D and 2D RNA nanostructures that were formed inside cells (Fig. 5a) [85]. Using these RNA assemblies, they demonstrated an organized [FeFe]-hydrogenase and ferredoxin reaction network which enhanced the biological hydrogen production up to 48-fold. A continuous study from the research group of Silver and coworkers showed that RNA scaffolds could be used to co-localize proteins and to increase the

A
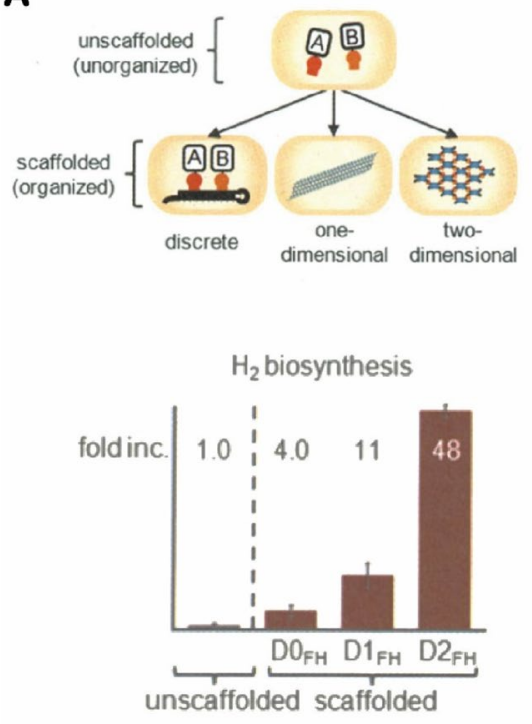

B

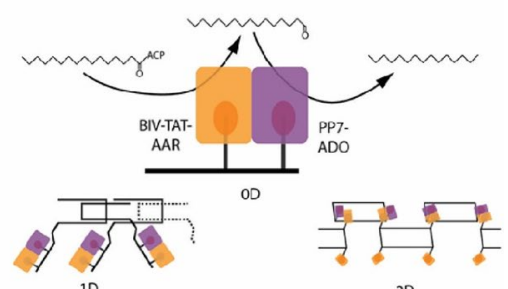

$2 \mathrm{D}$

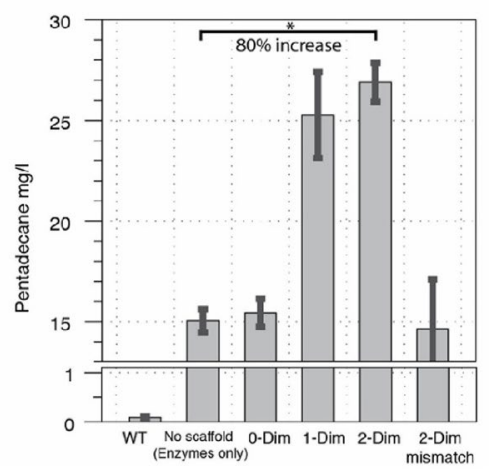

Fig. 5 In vivo assembly of enzyme cascades on RNA nanostructures. a Organization of [FeFe]-hydrogenase and ferredoxin on one-dimensional (1D) and 2D RNA nanostructures (top) with enhanced hydrogen production in vivo (bottom). Reproduced from Delebecque et al. [85], with permission, copyright 2011, The American Association for the Advancement of Science. b Assembly of a two-enzyme pentadecane production pathway on RNA scaffolds (top) with enhanced pentadecane output in vivo (bottom). Reproduced from Sachdeva et al. [86], with permission, copyright 2014, Oxford University Press 
metabolic output of a two-enzyme pentadecane production pathway in Escherichia coli (Fig. 5b) [86]. Nevertheless, potential applications of RNA scaffolds face challenges in terms of in vivo stability, survival of engineered cells, and loss of RNA information during cell division.

DNA nanostructure-organized systems offer an opportunity for investigating the detailed kinetics of enzyme cascade reactions. One conception of the past several decades is that the proximity of enzymes promotes the mass transport of intermediate substrates between enzymes, which in turn boosts the overall activity of enzyme cascade reactions $[6,87,88]$. This theory/hypothesis seems to be supported by some recent studies of assembled enzyme cascades on DNA scaffolds [44, 45, 80, 81, 85] and metabolon engineering [8, 89], in which multienzyme complexes reacted with proximity assembly more actively than did unassembled and freely diffused enzymes. However, this hypothesis is problematic if we consider the fact that many small-molecule substrates diffuse quite quickly in solution, with diffusion coefficients ranging from 100 to $1000 \mu \mathrm{m}^{2} / \mathrm{s}$. To interpret the diffusion, Fu et al. described the concentration profile of a $\mathrm{H}_{2} \mathrm{O}_{2}$ intermediate in a coupled $\mathrm{GOx}-\mathrm{HRP}$ reaction by Brownian motion (Fig. 6a), which was simulated based on Eq. (1): [45]

$$
n(r, t)=\sum_{i=0}^{i=\frac{t}{\tau}-1} \frac{1}{(4 \pi D(t-i \times \tau))^{\frac{3}{2}}} \times \exp \left(-\frac{r^{2}}{4 D(t-i \times \tau)}\right),
$$

where $n(r, t)$ is the number of molecules at a distance $r$ from the initial produced position of production, $D$ is the diffusion coefficient and $t$ is the time given for diffusion. When the Brownian motion of $\mathrm{H}_{2} \mathrm{O}_{2}$ is considered in a GOx-HRP reaction in the given $t, \tau$ is the average time between GOx turnovers $(\tau=1 / k$, where $k$ is the

A

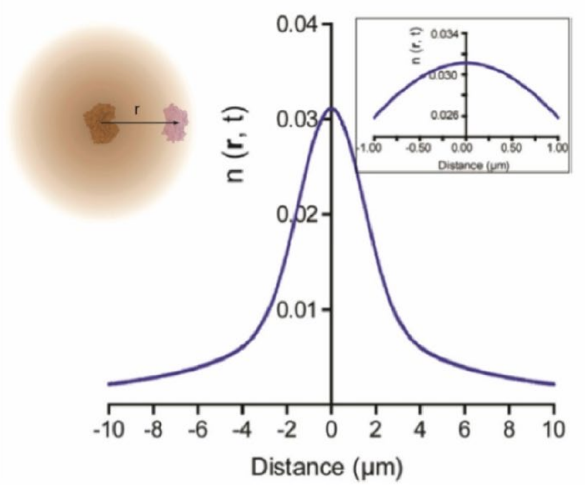

B

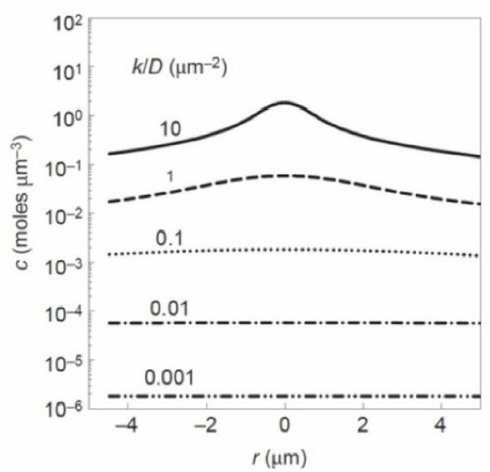

Fig. 6 Theoretical modeling of distance-dependent enzyme cascade reactions. a Brownian diffusion of $\mathrm{H}_{2} \mathrm{O}_{2}$ in a GOx/HRP reaction depending on distance $[n(r, t)$ Number of molecules at a distance $r$ from the initial produced position of production]. Reproduced from $\mathrm{Fu}$ et al. [45], with permission, copyright 2012, American Chemical Society. b Concentration profiles of the reaction product as a function of radial distance $(r)$ from an active site under different ratios of turnover frequency to diffusion coefficient $(k / D)$. Reproduced from Wheeldon et al. [90], with permission, copyright 2016, Springer Nature 
turnover rate). The simulation of the diffusion profile showed that $\mathrm{H}_{2} \mathrm{O}_{2}$ concentrations varied slightly $(<5 \%)$ within a few hundred nanometers of GOx due to the fast diffusion of $\mathrm{H}_{2} \mathrm{O}_{2}\left(D \sim 1000 \mu \mathrm{m}^{2} / \mathrm{s}\right)$. This simulation result suggests that the proximity between enzymes has little benefits on the diffusion of $\mathrm{H}_{2} \mathrm{O}_{2}$ from GOx to HRP. As shown in Fig. 6b, Wheeldon et al. applied Eq. (1) to simulating the concentrations of product molecules at discrete distances from the active site of an enzyme as a function of $k / D$ [90]. For most enzymes, the diffusion coefficients (generally $\sim 100$ to $1000 \mu \mathrm{m}^{2} / \mathrm{s}$ ) of the small-molecule products were much larger than the turnover rates (generally $\sim 1-100 \mathrm{~s}^{-1}$ ), resulting in a small value of $k / D(0<k / D<1)$. Thus, product concentration profiles are spanned quite uniformly over a few micrometers distance, a result which also indicates the minimal effect of spatial proximity on the concentration of intermediates in a cascade reaction. Hess and coworkers mathematically modeled the reaction-diffusion kinetics of a GOx-HRP cascade reaction [91, 92]. The simulation of cascade kinetics showed that proximity did not contribute to the activity enhancement of the assembled GOx-HRP pairs. Other more recent reaction-diffusion modelings suggested that a close proximity between enzymes could only enhance the rate of a cascade reaction under crowding conditions where the diffusion of enzymes and substrates was significantly slowed down [93]. Similar modeling techniques have also been applied to in vivo metabolic pathways, which likewise showed that diffusion was not a rate-limiting factor for many enzyme systems and, therefore, proximity or substrate channeling would not significantly increase the overall rate of the cascade reaction at steady state $[88,93]$. Thus, substrate channeling is more likely used to regulate metabolite flux, improve pathway selectivity and protect metabolites from degradation or competing side reactions [88, 93].

Since proximity-enhanced mass-transport effect may not contribute to the activity enhancement of enzyme assemblies directed by DNA/RNA scaffolds or protein scaffolds, some recent studies have focused on the effects of assembly scaffolds themselves on altering enzyme kinetics, with the aim to provide unique microenvironments that favor stronger activity [88, 94, 95]. Such effects include modifying the local $\mathrm{pH}$ [96], including a hydration layer [94] and exerting an inhibitory effect [97]. Scaffolded microenvironments will be discussed in more detail in next section Enzyme Compartmentalization by DNA Nanocages. For non-freely diffused systems (e.g. constrained diffusion on a surface or within a compartment), the appropriate organization of multienzyme systems is still essential to maximize the efficiency of the system [47]. Some recent modeling studies have provided novel perspectives on enzyme assemblies on surfaces [98, 99] or within compartments $[100,101]$.

\section{Enzyme Compartmentalization by DNA Nanocages}

Many metabolic pathways are organized by confinement within membrane-delimited or membrane-free compartments, such as mitochondria, lysosomes, peroxisomes, carboxysomes and metabolosomes [102]. Compartmentalization affects biochemical reactions in many ways: by increasing local concentrations, facilitating mass transport of reaction intermediates, reducing toxicity of intermediates and 
protecting encapsulated contents from competing pathways [103]. Compartmentalization also plays a functional role in the chaperone-assisted folding of tertiary and quaternary protein structures and by preventing proteins from aggregating under cellular stress conditions [104]. Results from recent studies show that nucleoli could promote structure maintenance of nuclear proteins by compartmentalization in the presence of stressors [105].

The assembly of a DNA nanocube was first reported by the research group of Seeman and coworkers in 1991 (Fig. 7a) [106]. However, the constructed cage was not tested for the encapsulation of proteins or other large biomolecules. In 2006, Turberfield and coworkers designed a DNA tetrahedron with each edge comprising a 20-bp double helix ( $7 \mathrm{~nm})$ (Fig. 7b) [107]. This tetrahedron was shown to encapsulate a small protein [cytochrome $c$ (inner diameter $\sim 3.5 \mathrm{~nm}$ )]. The research group of Fan and coworkers very recently reported that the electroactivity of cytochrome $c$ is enhanced on tetrahedral DNA frameworks [108]. As shown in Fig. 7c, DNA polyhedra have been used to organize streptavidin proteins into various 3D patterns [109]. To encapsulate larger proteins, DNA origami nanocages have been designed with larger inner cavities that range from 10 to $50 \mathrm{~nm}$ [110]. Zhao et al. developed a general approach to encapsulate enzymes within a fully closed DNA nanocage (Fig. 7d) [94]. In their method, enzymes are first anchored onto open, half cages at a very high yield (>90\%), following which two half cages are combined into a closed cage by adding bridge strands [94]. Sprengel et al. reported the selective encapsulation of a protein guest into a DNA origami hollow cage by decorating multiple ligands

A

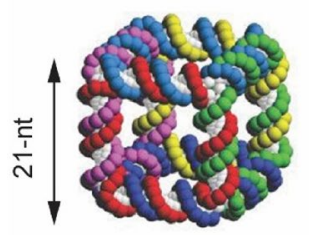

B
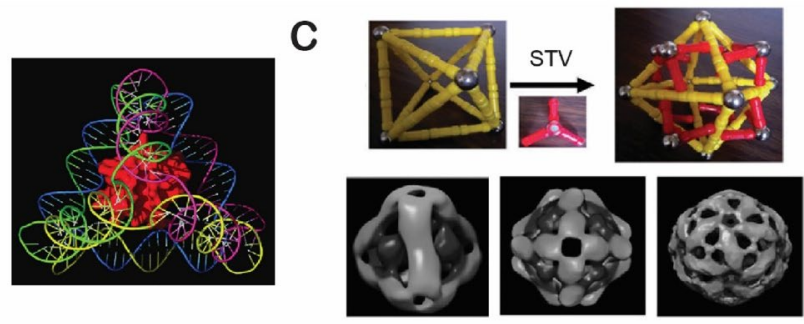

E
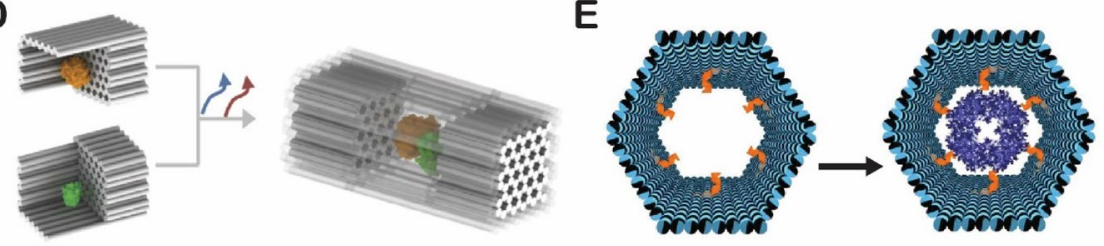

Fig. 7 Development of DNA nanocages for enzyme encapsulation. a The first 3D DNA cube. Reproduced from Seeman [19], with permission, copyright 2003, Springer Nature. b A DNA tetrahedron for encapsulating a protein. Reproduced from Erben et al. [107], with permission, copyright 2006, John Wiley and Sons. c DNA polyhedrons for organizing proteins (STV streptavidin). Reproduced from Zhang et al. [109], with permission, copyright 2019, John Wiley and Sons. d The combination of half DNA nanocages for enclosing enzymes. Reproduced from Zhao et al. [94], with permission, copyright 2016, Springer Nature. e Protein encapsulation into a DNA host using noncovalent protein-ligand interactions. Reproduced from Sprengel et al. [72] under the terms and conditions of the Creative Commons Attribution 4.0 International License, copyright 2017, Springer Nature 
on the inner surface of the cage to guide supramolecular interactions (Fig. 7e) [72]. This noncovalent protein-ligand binding enabled the capture of very large protein complexes (up to $\operatorname{DegP}_{24}, \sim 1$ million Da) into a well-defined DNA host.

Regarding smart nanoreactors, switchable DNA nanocages have been designed to regulate the encapsulation and release of protein payloads. As shown in Fig. 8a, Fan and coworkers developed a single-step wrap-over of a planar DNA origami sheet into nanoribbons and nanotubes which they used to encapsulate enzyme cascades [80]. The research group of Knudsen and coworkers designed a temperaturesensitive DNA nanocage which exhibited a closed conformation at $4{ }^{\circ} \mathrm{C}$ and an open conformation at $37{ }^{\circ} \mathrm{C}$ (Fig. 8b) [111]. This switchable nanocage was used to encapsulate and release HRP in response to temperature. Kohman et al. reported a light-triggered release of bioactive cargoes of proteins and small molecules from a DNA nanocage through the incorporation of a photolabile crosslinker (Fig. 8c) [112]. An $o$-nitrobenzyl motif was photocleavable upon ultraviolet (UV) radiation at $240-400 \mathrm{~nm}$ to release a linked cargo of protein or small molecules. Kim et al. designed a $\mathrm{pH}$-switchable DNA tetrahedron for regulating protein stability against protease digestion, protein-antibody binding and enzyme activity (Fig. 8d) [113]. Andersen and coworkers designed a DNA nanovault to control the access of substrate molecules to encapsulated enzymes by the reversible opening (accessible to substrate) and closing (inaccessible) of the cage (Fig. 8e) [114].

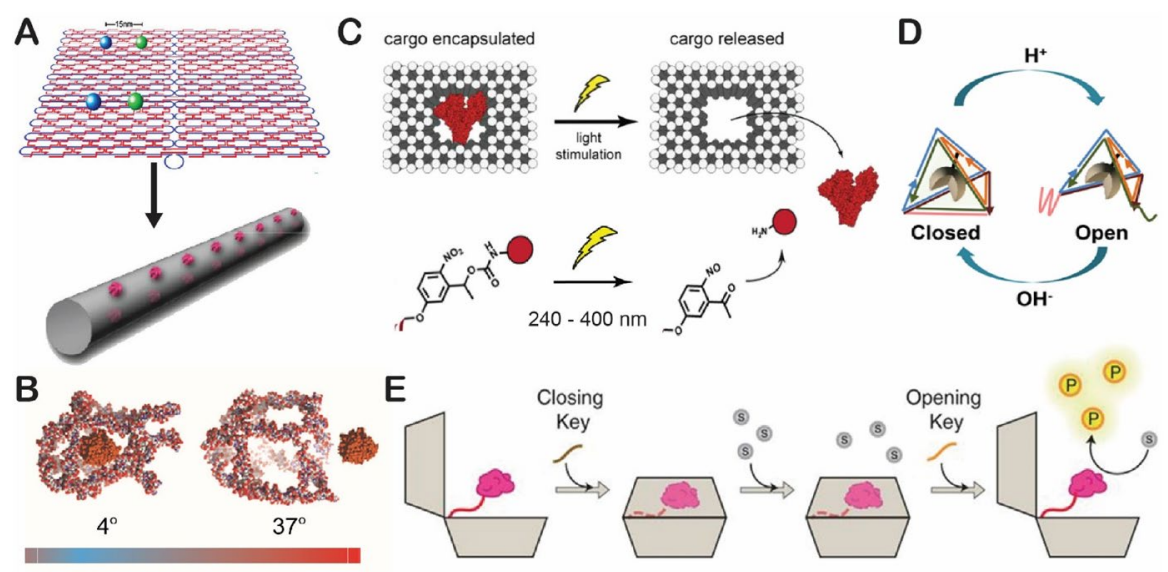

Fig. 8 DNA nanocage-regulated encapsulation and release of protein cargoes. a Single-step folding of DNA nanotubes for enzyme encapsulation. Reproduced from Fu et al. [80], with permission, copyright 2013, American Chemical Society. b A temperature-sensitive DNA nanocage for encapsulating and releasing an enzyme. Reproduced from Juul et al. [111], with permission, copyright 2013, American Chemical Society. c A light-triggered release of bioactive cargoes from a DNA nanocage. Reproduced from Kohman et al. [112], with permission, copyright 2016, American Chemical Society. d A pH-switchable DNA tetrahedron for regulating protein stability and activity. Reproduced from Kim et al. [113], with permission, copyright 2017, American Chemical Society. e A DNA nanovault with reversible opening and closing to regulate enzyme-substrate accessibility. Reproduced from Grossi et al. [114] under the terms and conditions of the Creative Commons Attribution 4.0 International License, copyright 2017, Springer Nature 
More interestingly, DNA nanoscaffolds have been found to affect the activities of the enzymes that were attached onto them. Figure 9 summarizes some of the DNA structures that have been reported to enhance enzyme activities [115], including a long dsDNA molecule (e.g. $\lambda$ DNA, 1-2 fold improved activity) [116], a DNA structure binding to enzyme substrates ( 1-2 fold) [117], a 2D rectangular DNA origami ( 1-3 fold) [45], DNA nanocaged enzymes ( 3-6 fold) [94, 118] and DNAcrowded enzyme particles ( $\sim-3$ fold) [95]. To better understand these effects, several mechanisms have been proposed to interpret DNA scaffolds-enhanced enzyme activities, including locally decreased $\mathrm{pH}$ on the DNA scaffolds [115], the presence of a stabilized hydration layer by DNA phosphate backbones [94], nanoconfinement of water [119], enrichment of substrate molecules on DNA scaffolds [117] and substrate channeling $[45,47]$. However, many questions still remain on just how DNA confinements modify the local chemical and physical environment and affect enzyme functions. Experiments combining experimental data with molecular modeling may shed light on the chaperone-like function of DNA nanocages.

\section{Biomimetic Assembly of Macromolecular Complexes}

Biomimetic systems represent one of the most exciting research frontiers in the twenty-first century. Life on earth has been diversifying for nearly four billion years, evolving into complex and diverse species. All living organisms have developed the appropriate functions and solutions to address the challenges of Earth's environment. Living systems have inspired humanity and provided the principles to solve problems and explore questions both in and out of the laboratory. Biomimetic materials have shown exciting potential in applications ranging from catalysis and energy transformation to smart materials, diagnostic tools and therapeutics [120]. Equally, structural DNA nanotechnology has been applied to engineering artificial systems mimicking cellular structures and biological functions. In the following paragraphs we list several examples of DNA-scaffolded biomimetic assemblies.

The swinging arm, or the covalently attached prosthetic group, is a key functional structure in substrate channeling in multistep catalytic transformations within metabolic pathways [121]. For example, a lipoyl-lysine arm is found in the pyruvate

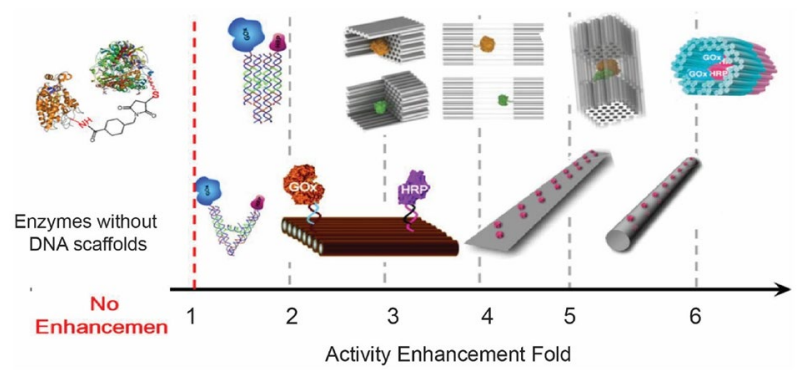

Fig. 9 Enhancement of enzyme activity by DNA nanostructures. Reproduced from Zhang and Hess [115], with permission, copyright 2017, American Chemical Society 
dehydrogenase complex (Fig. 10a); this arm transfers acetyl CoA and carries out oxidation and reduction between three enzymes [122]. To mimic this, Fu et al. designed an $\mathrm{NAD}^{+}$-modified DNA arm that facilitated the hydride transfer between two dehydrogenases [47]. As shown in Fig. 10b, a two-enzyme cascade consisting of a glucose-6-phosphate dehydrogenase (G6PDH) and a malate dehydrogenase $(\mathrm{MDH})$ was displayed on a DX tile. An $\mathrm{NAD}^{+}$-modified poly $(\mathrm{T})_{20}$ was placed halfway between G6PDH and MDH. The activity of the cascade was enhanced by approximately 90 -fold by substrate channeling of one $\mathrm{NAD}^{+}$arm (Fig. 10c). Adjusting the number of swinging arms produced even more activity enhancement. As shown in Fig. 10d, the reaction specificity of the G6PDH-MDH cascade was also increased in the presence of a competing enzyme of lactate dehydrogenase (LDH). $\mathrm{NAD}^{+}$-modified DNA arms have also been successfully used to regulate the pathway direction between G6PDH-MDH and G6PDH-LDH [123], with the directional regulation of enzyme pathways controlled by DNA strand displacement [123] or the photo-responsive reaction (Fig. 11a) [124]. Additionally, swinging arms have been used to organize $\mathrm{NAD}^{+}$transfer in a $2 \mathrm{D}$ enzyme array of G6PDH and LDH (Fig. 11b) [125].

DNA-based swinging arms can also facilitate electron transfer in bioelectroactive systems. The research group of Wilner and coworkers used a DNA scaffold to organize the spatial interaction of a GOx enzyme with an electrode surface to generate an
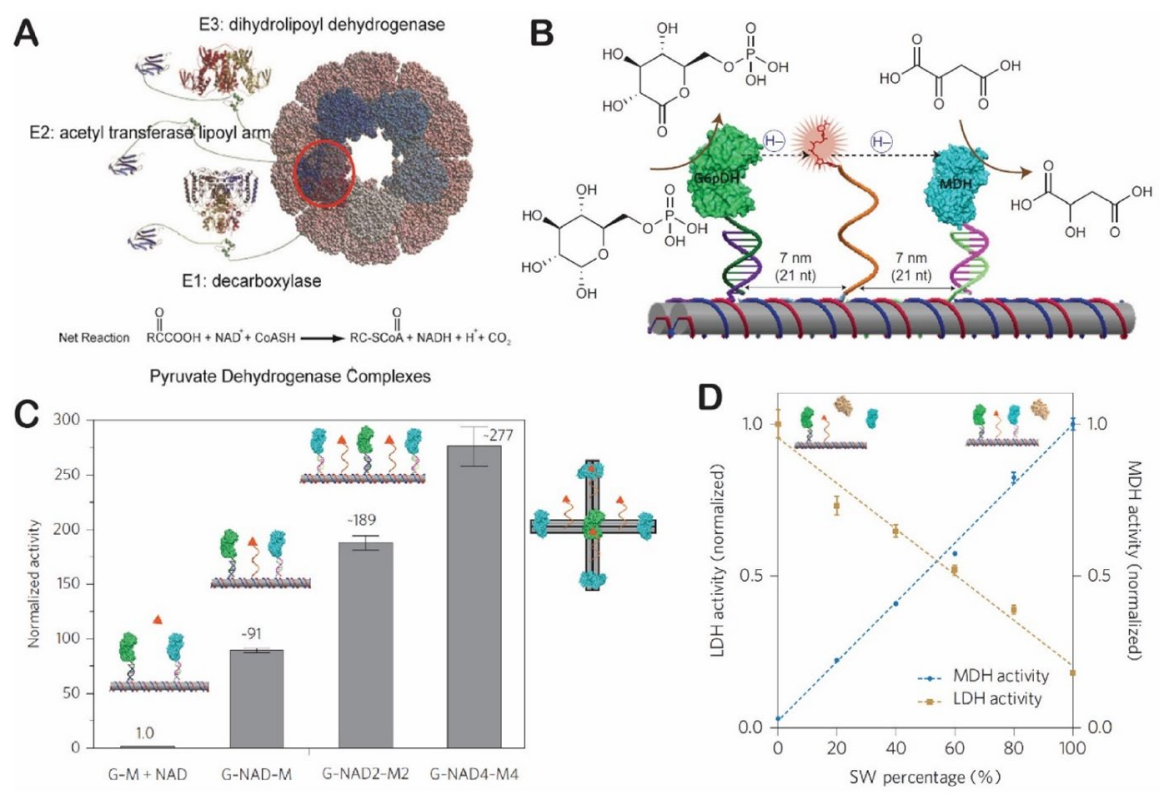

Fig. 10 Biomimetic assembly of swinging arms. a Swinging domains in pyruvate dehydrogenase complex. Reproduced from Perham [121], with permission, copyright 2000, Annual Review of Biochemistry. b An artificial swinging arm to transfer NAD ${ }^{+}$cofactor between two dehydrogenases (G6PDH glucose6-phosphate dehydrogenase and $\mathrm{MDH}$ ) on DNA nanoscaffolds. $\mathbf{c}$ Enhanced enzyme cascade activity by swinging arms. d Improved reaction selectivity by swinging arms. Reproduced from Fu et al. [47], with permission, copyright 2014, Springer Nature 


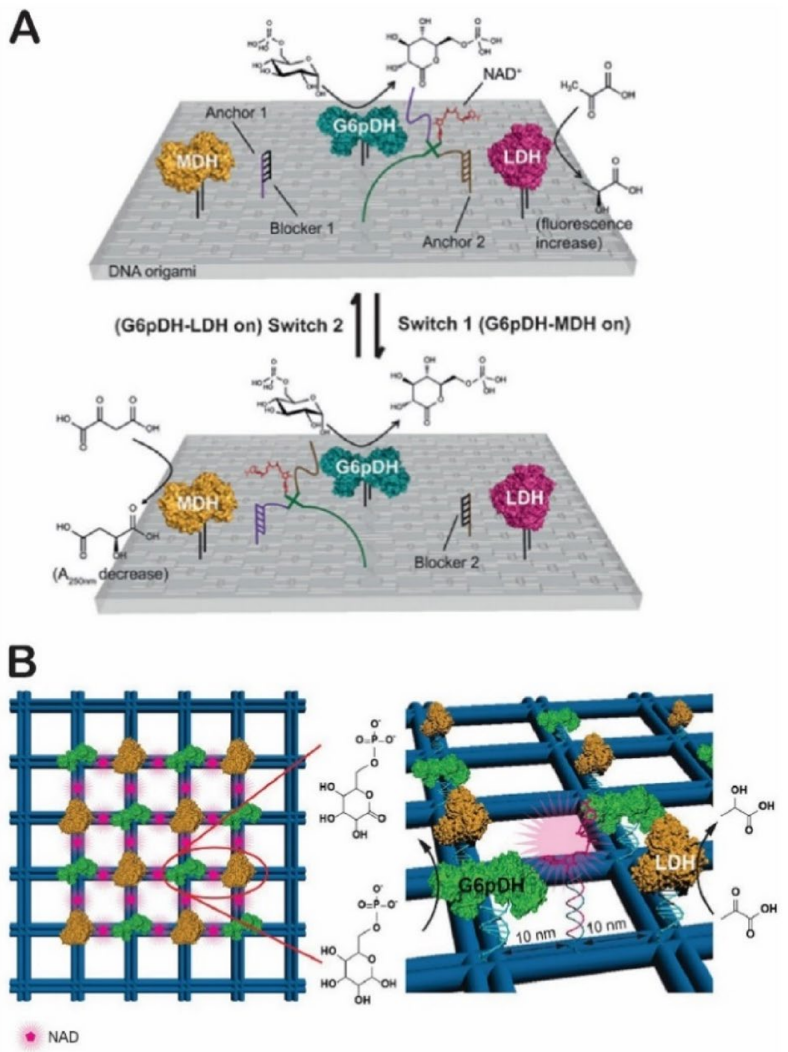

Fig. 11 Large biomolecular nanostructures organized by artificial swinging arms. a NAD ${ }^{+}$arms for regulating pathway activity between the G6PDH-MDH cascade and the G6PDH-LDH cascade. Reproduced from Ke et al. [123], with permission, copyright 2016, John Wiley and Sons. b 2D enzyme arrays of the G6PDH-MDH reaction with $\mathrm{NAD}^{+}$swinging arms. Reproduced from Yang et al. [125], with permission, copyright 2018, John Wiley and Sons

anodic electrocatalytic current (Fig. 12a) [126]. In this organized system, a ferrocene-modified ssDNA served as a relay to transfer electrons between the enzyme redox center and the electrode surface. As shown in Fig. 12b, Armand Tepper used DNA scaffolds to organize the electrochemical contact of redox enzymes and the electrode surface by immobilizing the copper enzyme of nitrite reductase (NiR) and its natural electron-exchange partner, pseudoazurin (Paz), onto a gold electrode by DNA scaffold-directed assembly [127]. Electron-transfer patches were realized by conjugating enzymes to specific ssDNA tags that allowed them to swing and perform nitrite reduction by accepting electrons from the gold electrode. As shown in Fig. 12c, Cha and coworkers used DNA scaffolds as a structure-directing template to organize $\mathrm{TiO}_{2}$ and CdS nanocrystals [128]. Enhanced hydrogen production was achieved when a benzoquinone (BQ)-modified ssDNA was used to transfer electrons between a $\mathrm{TiO}_{2}$ and a $\mathrm{CdS}$. 


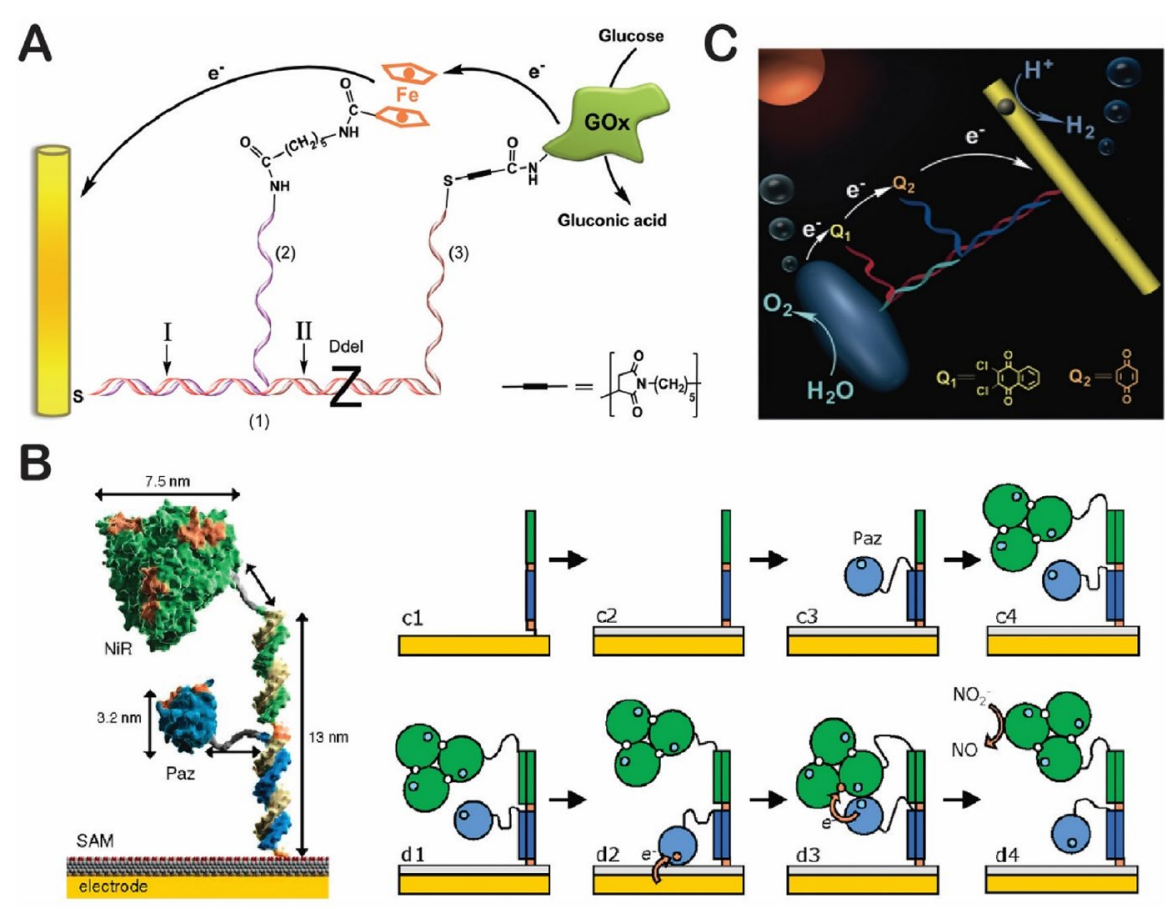

Fig. 12 DNA swinging arms for facilitating bioelectroactive reactions. a A GOx-ferrocene-electrode contact. Reproduced from Piperberg et al. [126], with permission, copyright 2009, American Chemical Society. b A nitrite reductase-pseudoazurin (NiR-Paz) system (SAM self-assembled monolayer). Reproduced from Tepper [127], with permission, copyright 2010, American Chemical Society. c A TiO ${ }_{2}-\mathrm{CdS}$ complex for $\mathrm{H}_{2}$ production. Reproduced from Ma et al. [128], with permission, copyright 2015, John Wiley and Sons

DNA-based molecular arms have also been useful in engineering nanorobotic systems and assembly lines. The research group of Simmel and coworkers studied the diffusive transport of DNA cargo strands that were bound to a DNA origami surface (Fig. 13a) [129]. These authors concluded that a more rigid DNA arm transferred cargo more efficiently than a more flexible, hinged arm. Based on this result, they developed a nanoscale robotic arm on a rectangular DNA origami tile, the rotation of which was driven and controlled by an electrical field (Fig. 13b) [130]. As shown in Fig. 13c, two research groups, namely those of Zhuang and coworkers and Yin and coworkers, collaborated to develop a DNA origami rotor that was driven by the unwinding function of a helicase (RecBCD complex) during the transcription process [131]. These authors introduced a method of origami-rotor-based imaging and tracking (ORBIT) to track DNA rotation at the single-molecule level with a time resolution of milliseconds.

In addition to swinging arms, DNA nanostructures can also be used to engineer artificial membrane transporters to facilitate the diffusion of ions and small molecules across lipid membranes [36]. Ohmann and co-workers recently designed a 


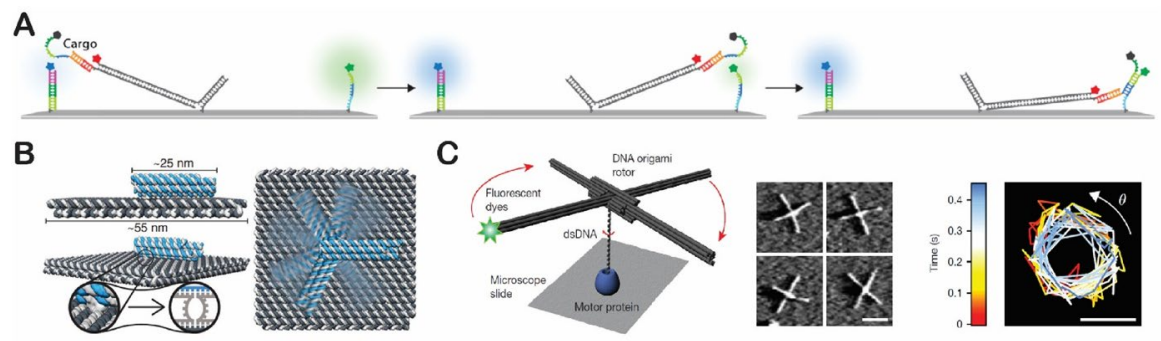

Fig. 13 DNA arm-based nanorobotic system. a Double-stranded DNA ( $d s D N A)$ arms for fluorescent cargo transport. Reproduced from Kopperger et al. [129], with permission, copyright 2015, American Chemical Society. b A nanoscale robotic arm driven by an electric field. Reproduced from Kopperger et al. [130], with permission, copyright 2018, The American Association for the Advancement of Science. c DNA origami rotor driven by a motor protein (left), atomic force microscopy images of a DNA rotor (middle) and origami-rotor-based imaging and tracking (ORBIT) for tracking DNA rotation (right). Reproduced from Kosuri et al. [131], with permission, copyright 2019, Springer Nature

synthetic scramblase built from DNA nanostructures [132]. As shown in Fig. 14a, the lipid-scrambling DNA nanostructure was made by the self-assembly of eight ssDNA with two cholesterol prosthetic groups to stabilize the inserted DNA structure in the lipid bilayer. Figure $14 \mathrm{~b}$ shows molecular dynamic simulations of the lipid scrambling process catalyzed by DNA nanostructures; this DNA-based scramblase could flip $10^{7}$ lipids per second, which is much faster than a natural enzyme $\left(\sim 3 \times 10^{4}\right.$ lipids per second $)$.

DNA scaffolding has also shown its value in more complex synthetic systems. Photosynthesis, for example, is an essential process that provides energy and oxygen for most living organisms on earth. The development of artificial photosynthetic systems, therefore, would present great opportunities in such areas as food and fuel production, energy transformation and catalysis, with broad social and economic impact. DNA nanostructures have been applied to engineering these artificial photosynthetic systems, particularly light-harvesting complexes. As shown in Fig. 15a,

A

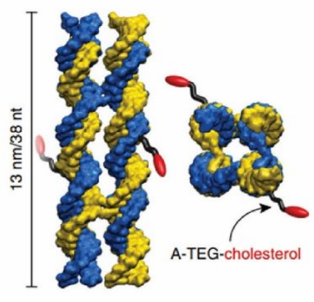

B

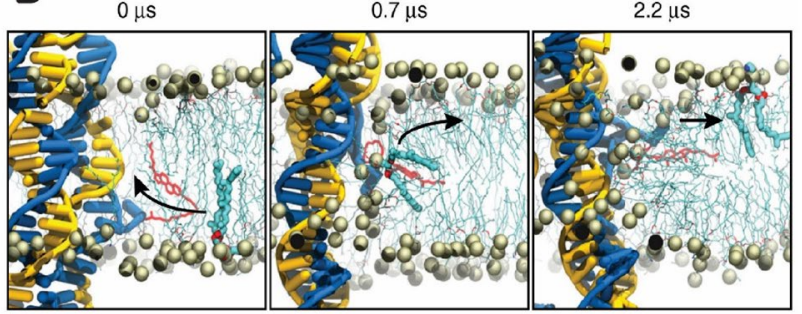

Fig. 14 Synthetic scramblase built from DNA. a The structure of a DNA-based scramblase with two cholesterol prosthetic groups. b Molecular dynamic simulation of the lipid scrambling process. Reproduced from Ohmann et al. [132] under the terms and conditions of the Creative Commons Attribution 4.0 International License, copyright 2018, Springer Nature 

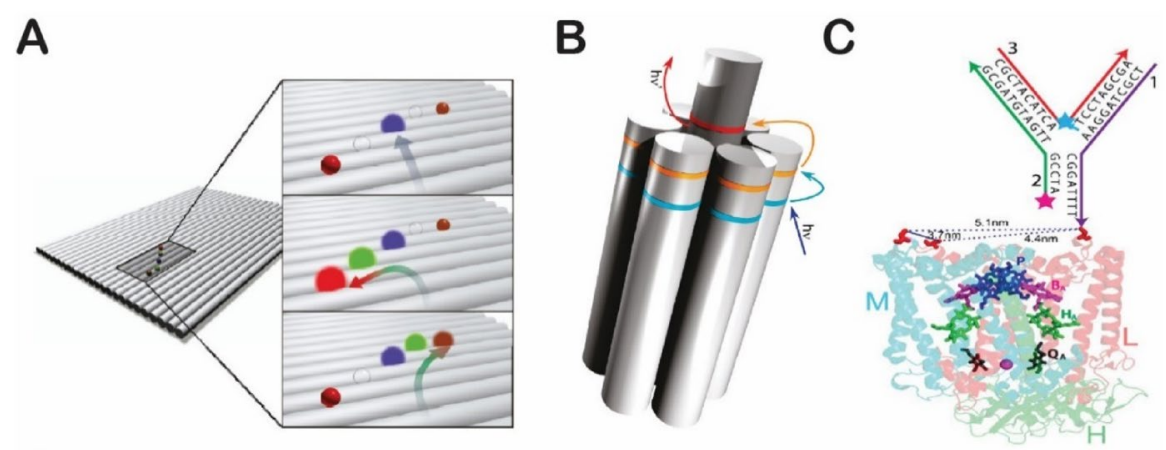

D

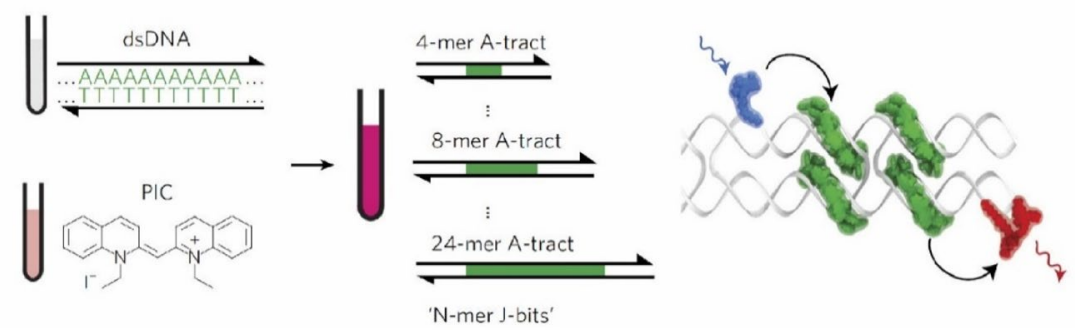

Fig. 15 Artificial photosynthetic systems organized by DNA nanoscaffolds. a Multicolor fluorophore array for photo-energy transfer. Reproduced from Stein et al. [133], with permission, copyright 2011, American Chemical Society. b Artificial light-harvesting network. Reproduced from Dutta et al. [134], with permission, copyright 2011, American Chemical Society. c A DNA-directed light-harvesting/reaction center. Reproduced from Dutta et al. [135], with permission, copyright 2014, American Chemical Society. d A synthetic DNA-based excitonic circuit based on J-aggregates (PIC pseudoisocyanine). Reproduced from Boulais et al. [136], with permission, copyright 2017, Springer Nature

Tinnefeld and coworkers were the first to report a multi-fluorophore array on a DNA origami tile; these researchers controlled the spacing distance and the position of each fluorophore to direct the energy transfer [133]. Yan and coworkers constructed an artificial light-harvesting antenna by assembling multiple donor/acceptor pairs on a seven-helix DNA bundle (Fig. 15b) [134]. In this system, stepwise funneling of the excitation energy was directed from the primary donor array (pyrylium [Py] dye) to the acceptor core (Alexa Fluor ${ }^{\circledR}[\mathrm{AF}]$ dye) through the intermediate donor (cyanine [Cy3] dye). In a collaboration with the research group of Woodbury and coworkers, Yan and coworkers also assembled a tunable artificial light-harvesting system which used a three-arm DNA nanostructure instead of a the seven-helix bundle (Fig. 15c). This structure was conjugated to a photosynthetic center protein and served as an antenna to transfer energy to the reaction center [135]. Recently, the research groups of Bathe and coworkers and Yan and coworkers worked together to develop a strategy to organize Cy3 dye aggregates on rigid dsDNA scaffolds. These dye/DNA aggregates showed a tunable absorption spectrum and strongly coupled exciton dynamics similar to that of natural light-harvesting systems (Fig. 15d) [136]. These DNA-templated dye aggregates can be used to engineer long-range, directional photo-energy transfer and harvest [137]. 


\section{Regulation of Proximity Interactions in Biochemical Reactions}

DNA nanostructures can be used to mediate the proximity assembly of enzymes and catalytic cofactors in order to regulate their reaction activities. Ghadiri and coworkers engineered an artificial allosteric enzyme by tethering a metalloprotease with an inhibitor-conjugated ssDNA, which they called an inhibitor-DNA-enzyme (IDE) construct (Fig. 16a) [138]. Due to the flexible ssDNA linker, the inhibitor was able to bind to the active site of an enzyme. The activation of this IDE was triggered by hybridizing the ssDNA linker with a complimentary ssDNA to form a dsDNA segment. The relatively rigid dsDNA blocked the inhibitor from binding to the active site, thus permitting the enzyme to function. This IDE structure was subsequently used to engineer molecular logic circuits by programmable DNA hybridizations [139]. As shown in Fig. 16b, the IDE was used to regulate the fibrinolytic activity that resulted from the binding of a streptokinase (SK) to the plasma proenzyme plasminogen $(\mathrm{Pg})$ [140], with the result being a DNA-linked protease inhibitor bound with a SK-Pg complex that inhibited fibrinolytic activity. Specific DNA inputs disrupted the inhibited binding complex, releasing an active SK-Pg complex. The research group of Merkx and coworkers used DNA-mediated assembly and disassembly to regulate enzyme-inhibitor binding to reversibly switching enzyme activity on and off (Fig. 16c) [141]. As shown in Fig. 16d, Tan and coworkers used a cis-trans photoisomerization of an azobenzene prosthetic group to regulate the binding of a thrombin with its aptamer [142]. In the cis-form of azobenzene, a

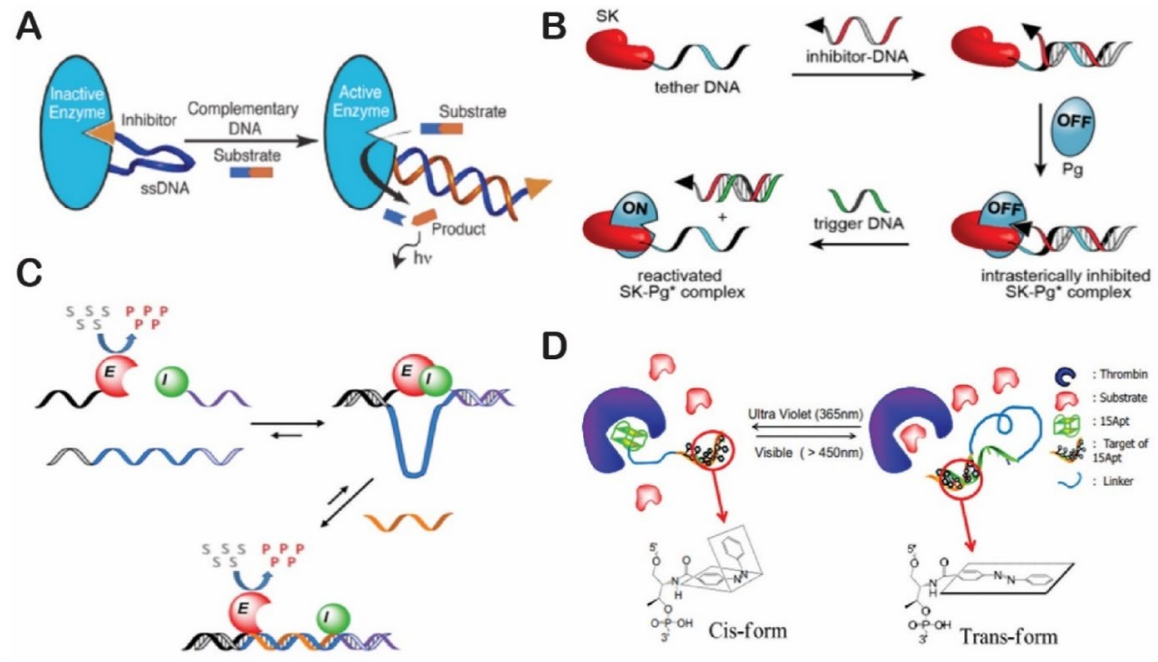

Fig. 16 DNA hybridization-regulated enzyme activity. a An enzyme-inhibitor interaction (ssDNA Single-stranded DNA). Reproduced from Saghatelian et al. [138], with permission, copyright 2003, American Chemical Society. b Streptokinase-plasminogen $(S K-P g)$ complex for regulating fibrinolytic activity. Reproduced from Mukherjee et al. [140], with permission, copyright 2018, American Chemical Society. c Enzyme actuation ( $E$ enzyme, $I$ inhibitor). Reproduced from Janssen [141], with permission, copyright 2015, American Chemical Society. d Photo-regulated thrombin-aptamer complex. Reproduced from Kim et al. [142], with permission, copyright 2009, National Academy of Sciences 
thrombin was bound to an DNA aptamer which inhibited thrombin-mediated coagulation. Upon UV irradiation, azobenzene switched the from cis-form to the transform, exposing a regulatory domain that disrupted the thrombin-aptamer complex, allowing the unbound thrombin to induce blood coagulation [142].

To engineer more complicated regulatory systems, DNA-based nanomachines were developed to regulate the spatial interactions between components of biochemical reactions. Liu and coworkers designed DNA nanotweezers to regulate the spacing distance between a G6PDH and a $\mathrm{NAD}^{+}$cofactor that were anchored on the two arms of DNA tweezers (Fig. 17a) [48]. By switching the DNA tweezers from the open to closed state, the activity of the enzyme and its cofactor was turned on. As shown in Fig. 17b, Liu and coworkers used similar DNA tweezers to regulate the spacing distance between a GOx and HRP with tunable activities [143], while Wilner and coworkers reported DNA nanomachines that could perform "ON/OFF" switchable activation and deactivation of a three-component biocatalytic cascade (Fig. 17c) [144]. When the tweezers were closed, the cascade reaction was activated by the formation of a hemin/G-quadruplex-bridged structure, but when the tweezers
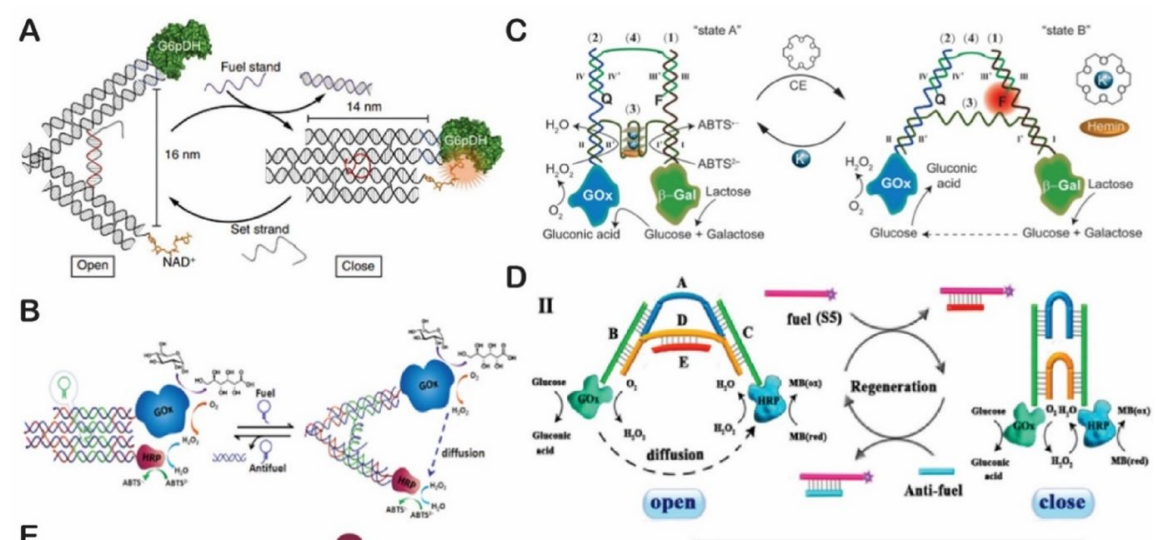

D

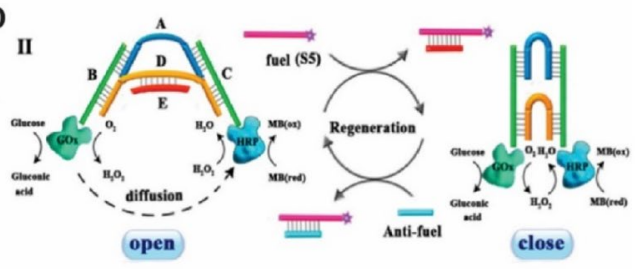

E
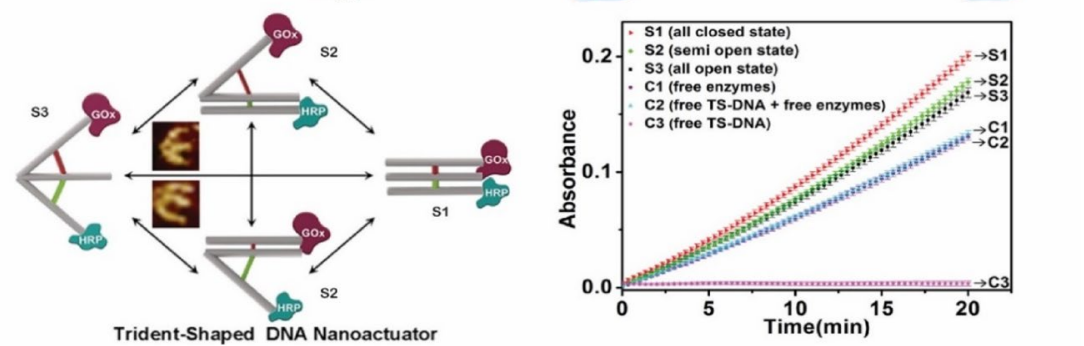

Fig. 17 DNA nanotweezers-regulated enzyme reaction. a A G6PDH/NAD ${ }^{+}$pair. Reproduced from Liu et al. [48], with permission. Copyright 2013, Springer Nature. b A GOx/HRP cascade. Reproduced from Xin et al. [143], with permission, copyright 2013, John Wiley and Sons. c A three-component biocatalytic cascade of $\beta-\mathrm{Gal} / \mathrm{GOx} / \mathrm{hemin}$. Reproduced from Hu et al. [144], with permission, copyright 2014, John Wiley and Sons. d Distance regulation of a GOx/HRP pair. Reproduced from Kou et al. [145], with permission, copyright 2018, American Chemical Society. e A trident-shaped DNA nanomachine with several conformational states for regulating an enzyme cascade. Reproduced from Xing et al. [146], with permission, copyright 2018, American Chemical Society 
were opened, the hemin/G-quadruplex was disrupted. DNA nanotweezers were also used by Kou et al. [145] to regulate the electrochemical response of a GOx/HRP cascade reaction (Fig. 17d). Yang and coworkers constructed a trident-shaped DNA nanoactuator that could switch between four distinct structural conformations [146]. As shown in Fig. 17e, different GOx/HRP activities could be achieved with each conformation of the trident-shaped DNA nanomachine. However, because many enzyme cascade reactions (e.g. GOx/HRP cascade) are not sensitive to enzyme proximity, as discussed previously [92], only small differences of enzyme cascade activities were observed for these four conformations of DNA tweezers. In contrast, DNA nanomachines were more efficient in regulating enzyme/cofactor pairs (which do rely on proximity interaction), with enhanced activities ranging from a few fold up to 100 -fold or more [48, 49].

Using a simpler approach, $\mathrm{Fu}$ and coworkers reported a method of using a DNA hairpin structure to mediate the proximity assembly of biochemical reactions (Fig. 18a) [49]. The self-folded DNA hairpin carried a cofactor that was not able to interact with its partner enzyme, resulting in very low catalytic activity. A triggered opening of the DNA hairpin was subsequently assembled with an enzyme to bring together the enzyme/cofactor pair for actuating the reaction with a 100-fold more activity. Based on this result, a biochemical sensing circuit was designed which combined a sensing module (made of DNA structural switches) with a triggered proximity assembly of an enzyme/cofactor pair. When the sensing module was activated by a target molecule, the enzyme could bind to the cofactor and catalyze a reaction to produce a detectable signal (Fig. 18b). This DNA-based sensing circuit could be used either for detecting microRNA (via strand displacement) or small-molecule metabolites, such as adenosine (using an aptamer) (Fig. 18c). DNA nanostructureregulated enzyme assemblies provide a new approach to programming enzyme
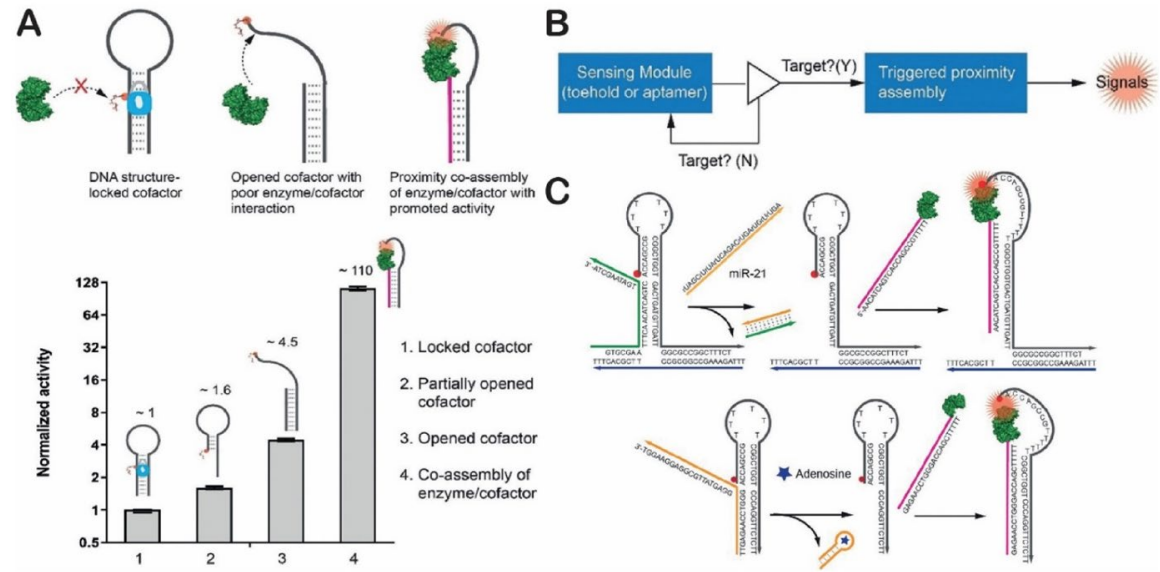

Fig. 18 DNA hairpin-mediated proximity assembly of an enzyme and a cofactor. a Enzyme activities for a hairpin-locked cofactor, opened cofactor and co-assembled enzyme/cofactor pair. b A design chart of a biochemical sensing circuit. c Detection of microRNA and adenosine. Reproduced from Oh et al. [49], with permission, copyright 2018, John Wiley and Sons 
activities. This may lead to the development of a new generation of enzyme-based diagnostic tools and therapeutics. They may also be used as a basis for developing protein feedback loops or allosteric regulation as an alternative or complementary technology to protein engineering.

\section{Conclusions and Future Perspectives}

Structural DNA nanotechnology has enabled the design and fabrication of various nano-objects with prescribed geometry and regulated spatial interaction. The combination of DNA nanostructures with enzyme-DNA conjugation provides an efficient approach for engineering artificial biomolecule complexes with finely controlled spatial arrangement and confinement. Considering these advantages together, it can be concluded that DNA nanostructures have the potential to deliver breakthroughs toward the engineering of more sophisticated biomimetic systems, such as synthetic cells, artificial subcellular components and photosynthetic and energy-harvesting structures. For example, DNA scaffolds can be used to organize multilevel assemblies for the construction of a synthetic reactor, including membrane confinement, artificial transmembrane nanopores and encapsulated biochemical reaction pathways [36]. Another potential use of DNA nanotechnology is the design and construction of dynamic and regulated structures with conformational switches triggered by external inputs. Dynamic nanostructures may find utility in the development of feedback-regulated biochemical systems. Some early examples have already demonstrated the feasibility of using DNA nanostructures to regulate enzyme activities, including inhibitor-DNA-enzyme structures, DNA tweezers and DNA swinging arms. It is possible to design substrate cooperativity or product feedback inhibition by incorporating aptamer switches into enzyme inhibition and activation complexes. Finally, diagnostic applications provide great challenges and opportunities to design DNA-based molecular circuits for sensing various molecular targets in vitro or in vivo. Smart DNA circuits can be adapted to various point-of-care diagnosis platforms, such as paper strips and color-change-based assays. This will fit the growing need for fast, sensitive and easy detection of infectious diseases, such as the recent outbreaks of coronavirus, Ebola and Zika virus that resulted in Public Health Emergencies of International Concern as announced by the World Health Organization. Overall, DNA-scaffolded enzyme assemblies will have a bright future and be useful in various applications of biocatalysis, functional biomaterials and novel theranostic medicine.

Acknowledgements This work was supported by a PECASE award to J.F. (W911NF1910240) and a DoD DURIP (W911NF-16-1-0220). J.F. is also supported by the Start-up Fund, Provost's Fund for Research and Research Council Grant from Rutgers University-Camden. X.L. is sponsored by MARC internship at Rutgers-Camden. The authors are also grateful to the Equipment Leasing Funds from the State of New Jersey.

Author Contributions The manuscript was written through contributions of all authors. All authors have given approval to the final version of the manuscript. 


\section{Compliance with Ethical Standards}

Conflict of interest The authors declare no competing financial interest.

\section{References}

1. Schomburg I, Chang A, Placzek S, Söhngen C, Rother M, Lang M, Munaretto C, Ulas S, Stelzer M, Grote A, Scheer M, Schomburg D (2013) BRENDA in 2013: integrated reactions, kinetic data, enzyme function data, improved disease classification: new options and contents in BRENDA. Nucleic Acids Res 41:D764-D772

2. Roach PJ (1977) Functional significance of enzyme cascade systems. Trends Biochem Sci 2:87-90

3. Savage DF, Afonso B, Chen AH, Silver PA (2010) Spatially ordered dynamics of the bacterial carbon fixation machinery. Science 327:1258-1261

4. Srere PA, Mosbach K (1974) Metabolic compartmentation: symbiotic, organellar, multienzymic, and microenvironmental. Annu Rev Microbiol 28:61-84

5. Bayer EA, Belaich JP, Shoham Y, Lamed R (2004) The cellulosomes: multienzyme machines for degradation of plant cell wall polysaccharides. Annu Rev Microbiol 58:521-554

6. Miles EW, Rhee S, Davies DR (1999) The molecular basis of substrate channeling. J Biol Chem 274:12193-12196

7. Yeates TO, Crowley CS, Tanaka S (2010) Bacterial microcompartment organelles: protein shell structure and evolution. Annu Rev Biophys 39:185-205

8. Dueber JE, Wu GC, Malmirchegini GR, Moon TS, Petzold CJ, Ullal AV, Prather KLJ, Keasling JD (2009) Synthetic protein scaffolds provide modular control over metabolic flux. Nat Biotechnol 27:753-759

9. Sheldon RA (2007) Cross-linked enzyme aggregates (CLEAs): stable and recyclable biocatalysts. Biochem Soc Trans 35:1583-1587

10. Sheldon RA (2007) Enzyme immobilization: the quest for optimum performance. Adv Synth Catal 349:1289-1307

11. Vriezema DM, Garcia PML, Sancho ON, Hatzakis NS, Kuiper SM, Nolte RJM, Rowan AE, van Hest Jan CM (2007) Positional assembly of enzymes in polymersome nanoreactors for cascade reactions. Angew Chem Int Ed Engl 46:7378-7382

12. van Dongen SFM, Nallani M, Cornelissen JJLM, Nolte RJM, van Hest JCMA (2009) Threeenzyme cascade reaction through positional assembly of enzymes in a polymersome nanoreactor. Chem Eur J 15:1107-1114

13. Kim KT, Meeuwissen SA, Nolte RJM, van Hest JCM (2010) Smart nanocontainers and nanoreactors. Nanoscale 2:844-858

14. Fiedler JD, Brown SD, Lau JL, Finn MG (2010) RNA-directed packaging of enzymes within viruslike particles. Angew Chem Int Ed Engl 49:9648-9651

15. Comellas-Aragones M, Engelkamp H, Claessen VI, Sommerdijk NAJM, Rowan AE, Christianen PCM, Maan JC, Verduin BJM, Cornelissen JJLM, Nolte RJM (2007) A virus-based single-enzyme nanoreactor. Nat Nanotechnol 2:635-639

16. Seeman NC (1982) Nucleic acid junctions and lattices. J Theor Biol 99:237-247

17. Fu TJ, Seeman NC (1993) DNA double-crossover molecules. Biochemistry 32:3211-3220

18. Zadegan RM, Norton ML (2012) Structural DNA nanotechnology: from design to applications. Int J Mol Sci 13:7149-7162

19. Seeman NC (2003) DNA in a material world. Nature 421:427-431

20. Rothemund PWK (2006) Folding DNA to create nanoscale shapes and patterns. Nature 440:297-302

21. Wei B, Dai M, Yin P (2012) Complex shapes self-assembled from single-stranded DNA tiles. Nature 485:623-626

22. Ke Y, Ong LL, Shih WM, Yin P (2012) Three-dimensional structures self-assembled from DNA bricks. Science 338:1177-1183

23. Dietz H, Douglas SM, Shih WM (2009) Folding DNA into twisted and curved nanoscale shapes. Science 325:725-730 
24. Han D, Pal S, Nangreave J, Deng Z, Liu Y, Yan H (2011) DNA origami with complex curvatures in three-dimensional space. Science 332:342-346

25. Veneziano R, Ratanalert S, Zhang K, Zhang F, Yan H, Chiu W, Bathe M (2016) Designer nanoscale DNA assemblies programmed from the top down. Science 352:1534

26. Benson E, Mohammed A, Gardell J, Masich S, Czeizler E, Orponen P, Hogberg B (2015) DNA rendering of polyhedral meshes at the nanoscale. Nature 523:441-444

27. Zhang F, Jiang S, Wu S, Li Y, Mao C, Liu Y, Yan H (2015) Complex wireframe DNA origami nanostructures with multi-arm junction vertices. Nat Nanotechnol 10:779-784

28. Ke Y, Ong LL, Sun W, Song J, Dong M, Shih WM, Yin P (2014) DNA brick crystals with prescribed depths. Nat Chem 6:994-1002

29. Zheng J, Birktoft JJ, Chen Y, Wang T, Sha R, Constantinou PE, Ginell SL, Mao C, Seeman NC (2009) From molecular to macroscopic via the rational design of a self-assembled 3D DNA crystal. Nature 461:74-77

30. Zhang F, Yan H (2017) DNA self-assembly scaled up. Nature 552:34-35

31. Han D, Qi X, Myhrvold C, Wang B, Dai M, Jiang S, Bates M, Liu Y, An B, Zhang F, Yan H, Yin P (2017) Single-stranded DNA and RNA origami. Science 358(6369):eaao2648. https://doi. org/10.1126/science.aao2648

32. Williams S, Lund K, Lin C, Wonka P, Lindsay S, Yan H (2008) Tiamat: a three-dimensional editing tool for complex DNA structures. Lect Notes Comput Sci 5347:99-101

33. Zadeh JN, Steenberg CD, Bois JS, Wolfe BR, Pierce MB, Khan AR, Dirks RM, Pierce NA (2011) NUPACK: analysis and design of nucleic acid systems. J Comput Chem 32:170-173

34. Douglas SM, Marblestone AH, Teerapittayanon S, Vazquez A, Church GM, Shih WM (2009) Rapid prototyping of 3D DNA-origami shapes with caDNAno. Nucleic Acids Res 37:5001-5006

35. Castro CE, Kilchherr F, Kim DN, Shiao EL, Wauer T, Wortmann P, Bathe M, Dietz H (2011) A primer to scaffolded DNA origami. Nat Methods 8:221-229

36. Fu J, Oh SW, Monckton K, Arbuckle-Keil G, Ke Y, Zhang T (2019) Biomimetic compartments scaffolded by nucleic acid nanostructures. Small. https://doi.org/10.1002/smll.201900256

37. Fu J, Liu M, Liu Y, Yan H (2012) Spatially-interactive biomolecular networks organized by nucleic acid nanostructures. Acc Chem Res 45:1215-1226

38. Fu J, Yang YR, Dhakal S, Zhao Z, Liu M, Zhang T, Walter NG, Yan H (2016) Assembly of multienzyme complexes on DNA nanostructures. Nat Protoc 11:2243-2273

39. Yang Y, Wang J, Shigematsu H, Xu W, Shih WM, Rothman JE, Lin C (2016) Self-assembly of size-controlled liposomes on DNA nanotemplates. Nat Chem 8:476-483

40. Zhang Z, Yang Y, Pincet F, Llaguno M, Lin C (2017) Placing and shaping liposomes with reconfigurable DNA nanocages. Nat Chem 9:653-659

41. Burns JR, Seifert A, Fertig N, Howorka S (2016) A biomimetic DNA-based channel for the ligandcontrolled transport of charged molecular cargo across a biological membrane. Nat Nanotechnol $11: 152-156$

42. Langecker M, Arnaut V, Martin TG, List J, Renner S, Mayer M, Dietz H, Simmel FC (2012) Synthetic lipid membrane channels formed by designed DNA nanostructures. Science 338:932-936

43. Niemeyer CM (2010) Semisynthetic DNA-protein conjugates for biosensing and nanofabrication. Angew Chem Int Ed Engl 49:1200-1216

44. Wilner OI, Weizmann Y, Gill R, Lioubashevski O, Freeman R, Willner I (2009) Enzyme cascades activated on topologically programmed DNA scaffolds. Nat Nanotechnol 4:249-254

45. Fu J, Liu M, Liu Y, Woodbury NW, Yan H (2012) Interenzyme substrate diffusion for an enzyme cascade organized on spatially addressable DNA nanostructures. J Am Chem Soc 134:5516-5519

46. Lu N, Pei H, Ge Z, Simmons CR, Yan H, Fan C (2012) Charge transport within a three-dimensional DNA nanostructure framework. J Am Chem Soc 134:13148-13151

47. Fu J, Yang YR, Johnson-Buck A, Liu M, Liu Y, Walter NG, Woodbury NW, Yan H (2014) Multienzyme complexes on DNA scaffolds capable of substrate channelling with an artificial swinging arm. Nat Nanotechnol 9:531-536

48. Liu M, Fu J, Hejesen C, Yang Y, Woodbury NW, Gothelf K, Liu Y, Yan H (2013) A DNA tweezeractuated enzyme nanoreactor. Nat Commun. https://doi.org/10.1038/ncomms3127

49. Oh SW, Pereira A, Zhang T, Li T, Lane A, Fu J (2018) DNA-mediated proximity-based assembly circuit for actuation of biochemical reactions. Angew Chem Int Ed Engl 57:13086-13090

50. El-Sagheer AH, Brown T (2012) Click nucleic acid ligation: applications in biology and nanotechnology. Acc Chem Res 45:1258-1267 
51. Khatwani SL, Kang JS, Mullen DG, Hast MA, Beese LS, Distefano MD, Taton TA (2012) Covalent protein-oligonucleotide conjugates by copper-free click reaction. Bioorg Med Chem 20:4532-4539

52. Witus LS, Francis M (2010) Site-specific protein bioconjugation via a pyridoxal 5'-phosphatemediated N-terminal transamination reaction. Curr Protoc Chem Biol 2:125-134

53. Takeda S, Tsukiji S, Ueda H, Nagamune T (2008) Covalent split protein fragment-DNA hybrids generated through N-terminus-specific modification of proteins by oligonucleotides. Org Biomol Chem 6:2187-2194

54. Gu GJ, Friedman M, Jost C, Johnsson K, Kamali-Moghaddam M, Plückthun A, Landegren U, Söderberg O (2013) Protein tag-mediated conjugation of oligonucleotides to recombinant affinity binders for proximity ligation. New Biotechnol 30:144-152

55. Rosen CB, Kodal ALB, Nielsen JS, Schaffert DH, Scavenius C, Okholm AH, Voigt NV, Enghild JJ, Kjems J, Tørring T, Gothelf KV (2014) Template-directed covalent conjugation of DNA to native antibodies, transferrin and other metal-binding proteins. Nat Chem 6:804-809

56. Trads JB, Tørring T, Gothelf KV (2017) Site-selective conjugation of native proteins with DNA. Acc Chem Res 50:1367-1374

57. Yan H, Park SH, Finkelstein G, Reif JH, LaBean TH (2003) DNA-templated self-assembly of protein arrays and highly conductive nanowires. Science 301:1882-1884

58. Niemeyer CM, Koehler J, Wuerdemann C (2002) DNA-directed assembly of bienzymic complexes from in vivo biotinylated NAD(P)H:FMN oxidoreductase and luciferase. ChemBioChem 3:242-245

59. Liu Y, Lin C, Li H, Yan H (2005) Aptamer-directed self-assembly of protein arrays on a DNA nanostructure. Angew Chem Int Ed Engl 44:4333-4338

60. Chhabra R, Sharma J, Ke Y, Liu Y, Rinker S, Lindsay S, Yan H (2007) Spatially addressable multiprotein nanoarrays templated by aptamer-tagged DNA nanoarchitectures. J Am Chem Soc 129:10304-10305

61. Liu X, Yan H, Liu Y, Chang Y (2011) Targeted cell-cell interactions by DNA nanoscaffold-templated multivalent bispecific aptamers. Small 7:1673-1682

62. Rinker S, Ke Y, Liu Y, Chhabra R, Yan H (2008) Self-assembled DNA nanostructures for distancedependent multivalent ligand-protein binding. Nat Nanotechnol 3:418-422

63. Zhou Y, Qi X, Liu Y, Zhang F, Yan H (2019) DNA nanoscaffold-assisted selection of femtomolar bivalent aptamers for human $\alpha$-thrombin with potent anticoagulant activity. Chembiochem 20(19):2494-2503

64. Williams BAR, Lund K, Liu Y, Yan H, Chaput JC (2007) Self-assembled peptide nanoarrays: an approach to studying protein-protein interactions. Angew Chem Int Ed Engl 46:3051-3054

65. Williams BAR, Diehnelt CW, Belcher P, Greving M, Woodbury NW, Johnston SA, Chaput JC (2009) Creating protein affinity reagents by combining peptide ligands on synthetic DNA scaffolds. J Am Chem Soc 131:17233-17241

66. Fruk L, Kuo C-H, Torres E (2009) Niemeyer CM (2009) Apoenzyme reconstitution as a chemical tool for structural enzymology and biotechnology. Angew Chem Int Ed Engl 48:1550-1574

67. Shen W, Zhong H, Neff D, Norton ML (2009) NTA directed protein nanopatterning on DNA origami nanoconstructs. J Am Chem Soc 131:6660-6661

68. Lovrinovic M, Spengler M, Deutsch C, Niemeyer CM (2005) Synthesis of covalent DNA-protein conjugates by expressed protein ligation. Mol BioSyst 1:64-69

69. Saccà B, Meyer R, Erkelenz M, Kiko K, Arndt A, Schroeder H, Rabe KS, Niemeyer CM (2010) Orthogonal protein decoration of DNA origami. Angew Chem Int Ed Engl 49:9378-9383

70. Tominaga J, Kemori Y, Tanaka Y, Maruyama T, Kamiya N, Goto M (2007) An enzymatic method for site-specific labeling of recombinant proteins with oligonucleotides. Chem Commun 43:401-403

71. Lovendahl KN, Hayward AN, Gordon WR (2017) Sequence-directed covalent protein-DNA linkages in a single step using HUH-Tags. J Am Chem Soc 139:7030-7035

72. Sprengel A, Lill P, Stegemann P, Bravo-Rodriguez K, Schöneweiß E-C, Merdanovic M, Gudnason D, Aznauryan M, Gamrad L, Barcikowski S, Sanchez-Garcia E, Birkedal V, Gatsogiannis C, Ehrmann M, Saccà B (2017) Tailored protein encapsulation into a DNA host using geometrically organized supramolecular interactions. Nat Commun 8:14472

73. Praetorius F, Dietz H (2017) Self-assembly of genetically encoded DNA-protein hybrid nanoscale shapes. Science 355(6331):eaam5488. https://doi.org/10.1126/science.aam5488 
74. Erkelenz M, Kuo CH, Niemeyer CM (2011) DNA-mediated assembly of cytochrome P450 BM3 subdomains. J Am Chem Soc 133:16111-16118

75. Mori Y, Ozasa S, Kitaoka M, Noda S, Tanaka T, Ichinose H, Kamiya N (2013) Aligning an endoglucanase Cel5A from Thermobifida fusca on a DNA scaffold: potent design of an artificial cellulosome. Chem Commun 49:6971-6973

76. Sun Q, Madan B, Tsai S-L, DeLisa MP, Chen W (2014) Creation of artificial cellulosomes on DNA scaffolds by zinc finger protein-guided assembly for efficient cellulose hydrolysis. Chem Commun 50:1423-1425

77. Sun Q, Chen W (2016) HaloTag mediated artificial cellulosome assembly on a rolling circle amplification DNA template for efficient cellulose hydrolysis. Chem Commun 52:6701-6704

78. Chen Q, Yu S, Myung N, Chen W (2017) DNA-guided assembly of a five-component enzyme cascade for enhanced conversion of cellulose to gluconic acid and $\mathrm{H}_{2} \mathrm{O}_{2}$. J Biotechnol 263:30-35

79. Wilner OI, Shimron S, Weizmann Y, Wang Z-G, Willner I (2009) Self-assembly of enzymes on DNA scaffolds: en route to biocatalytic cascades and the synthesis of metallic nanowires. Nano Lett 9:2040-2043

80. Fu Y, Zeng D, Chao J, Jin Y, Zhang Z, Liu H, Li D, Ma H, Huang Q, Gothelf KV, Fan C (2013) Single-step rapid assembly of DNA origami nanostructures for addressable nanoscale bioreactors. J Am Chem Soc 135:696-702

81. Ngo TA, Nakata E, Saimura M, Morii T (2016) Spatially organized enzymes drive cofactor-coupled cascade reactions. J Am Chem Soc 138:3012-3021

82. Nguyen TM, Nakata E, Saimura M, Dinh H, Morii T (2017) Design of modular protein tags for orthogonal covalent bond formation at specific DNA sequences. J Am Chem Soc 139:8487-8496

83. Liu M, Fu J, Qi X, Wootten S, Woodbury NW, Liu Y, Yan H (2016) A three-enzyme pathway with an optimised geometric arrangement to facilitate substrate transfer. Chembiochem 17:1097-1101

84. Afonin KA, Bindewald E, Yaghoubian AJ, Voss N, Jacovetty E, Shapiro BA, Jaeger L (2010) In vitro assembly of cubic RNA-based scaffolds designed in silico. Nat Nanotechnol 5:676-682

85. Delebecque CJ, Lindner AB, Silver PA, Aldaye FA (2011) Organization of intracellular reactions with rationally designed RNA assemblies. Science 333:470-474

86. Sachdeva G, Garg A, Godding D, Way JC, Silver PA (2014) In vivo co-localization of enzymes on RNA scaffolds increases metabolic production in a geometrically dependent manner. Nucleic Acids Res 42:9493-9503

87. Bauler P, Huber G, Leyh T, McCammon JA (2010) Channeling by proximity: the catalytic advantages of active site colocalization using brownian dynamics. J Phys Chem Lett 1:1332-1335

88. Sweetlove LJ, Fernie AR (2018) The role of dynamic enzyme assemblies and substrate channelling in metabolic regulation. Nat Commun 9:2136

89. You C, Myung S, Zhang YHP (2012) Facilitated substrate channeling in a self-assembled trifunctional enzyme complex. Angew Chem Int Ed Engl 51:8787-8790

90. Wheeldon I, Minteer SD, Banta S, Barton SC, Atanassov P, Sigman M (2016) Substrate channelling as an approach to cascade reactions. Nat Chem 8:299-309

91. Idan O, Hess H (2012) Diffusive transport phenomena in artificial enzyme cascades on scaffolds. Nat Nanotechnol 7:769-770

92. Zhang Y, Tsitkov S, Hess H (2016) Proximity does not contribute to activity enhancement in the glucose oxidase-horseradish peroxidase cascade. Nat Commun 7:13982. https://doi.org/10.1038/ ncomms 13982

93. Kuzmak A, Carmali S, von Lieres E, Russell AJ, Kondrat S (2019) Can enzyme proximity accelerate cascade reactions? Sci Rep 9:455. https://doi.org/10.1038/s41598-018-37034-3

94. Zhao Z, Fu J, Dhakal S, Johnson-Buck A, Liu M, Zhang T, Woodbury NW, Liu Y, Walter NG, Yan $H$ (2016) Nanocaged enzymes with enhanced catalytic activity and increased stability against protease digestion. Nat Commun 7:10619. https://doi.org/10.1038/ncomms10619

95. Collins J, Zhang T, Oh SW, Maloney R, Fu J (2017) DNA-crowded enzyme complexes with enhanced activities and stabilities. Chem Commun 53:13059-13062

96. Zhang Y, Wang Q, Hess H (2017) Increasing enzyme cascade throughput by pH-engineering the microenvironment of individual enzymes. ACS Catal 7:2047-2051

97. Jørgensen K, Rasmussen AV, Morant M, Nielsen AH, Bjarnholt N, Zagrobelny M, Bak S, Møller BL (2005) Metabolon formation and metabolic channeling in the biosynthesis of plant natural products. Curr Opin Plant Biol 8:280-291

98. Roberts CC, Chang CA (2015) Modeling of enhanced catalysis in multienzyme nanostructures: effect of molecular scaffolds, spatial organization, and concentration. J Chem Theory Comput 11:286-292 
99. Chado GR, Stoykovich MP, Kaar JL (2016) Role of dimension and spatial arrangement on the activity of biocatalytic cascade reactions on scaffolds. ACS Catal 6:5161-5169

100. Tsitkov S, Hess H (2019) Design principles for a compartmentalized enzyme cascade reaction. ACS Catal 9:2432-2439

101. Tsitkov S, Pesenti T, Palacci H, Blanchet J, Hess H (2018) Queueing theory-based perspective of the kinetics of "channeled" enzyme cascade reactions. ACS Catal 8:10721-10731

102. Kerfeld CA, Heinhorst S, Cannon GC (2010) Bacterial microcompartments. Annu Rev Microbiol 64:391-408

103. Chen AH, Silver PA (2012) Designing biological compartmentalization. Trends Cell Biol 22:662-670

104. Hartl FU (1996) Molecular chaperones in cellular protein folding. Nature 381:571-580

105. Frottin F, Schueder F, Tiwary S, Gupta R, Körner R, Schlichthaerle T, Cox J, Jungmann R, Hartl FU, Hipp MS (2019) The nucleolus functions as a phase-separated protein quality control compartment. Science 365:342-347

106. Chen J, Seeman NC (1991) Synthesis from DNA of a molecule with the connectivity of a cube. Nature 350:631-633

107. Erben CM, Goodman RP, Turberfield AJ (2006) Single-molecule protein encapsulation in a rigid DNA cage. Angew Chem Int Ed Engl 45:7414-7417

108. Ge Z, Su Z, Simmons CR, Li J, Jiang S, Li W, Yang Y, Liu Y, Chiu W, Fan C, Yan H (2019) Redox engineering of cytochrome $c$ using DNA nanostructure-based charged encapsulation and spatial control. ACS Appl Mater Interfaces 11:13874-13880

109. Zhang C, Tian C, Guo F, Liu Z, Jiang W, Mao C (2012) DNA-directed three-dimensional protein organization. Angew Chem Int Ed Engl 51:3382-3385

110. Zhao Z, Jacovetty EL, Liu Y, Yan H (2011) Encapsulation of gold nanoparticles in a DNA origami cage. Angew Chem Int Ed Engl 50:2041-2044

111. Juul S, Iacovelli F, Falconi M, Kragh SL, Christensen B, Frøhlich R, Franch O, Kristoffersen EL, Stougaard M, Leong KW, Ho Y-P, Sørensen ES, Birkedal V, Desideri A, Knudsen BR (2013) Temperature-controlled encapsulation and release of an active enzyme in the cavity of a self-assembled DNA nanocage. ACS Nano 7:9724-9734

112. Kohman RE, Cha SS, Man H-Y, Han X (2016) Light-triggered release of bioactive molecules from DNA nanostructures. Nano Lett 16:2781-2785

113. Kim SH, Kim K-R, Ahn D-R, Lee JE, Yang EG, Kim SY (2017) Reversible regulation of enzyme activity by $\mathrm{pH}$-responsive encapsulation in DNA nanocages. ACS Nano 11:9352-9359

114. Grossi G, Dalgaard Ebbesen Jepsen M, Kjems J, Andersen ES (2017) Control of enzyme reactions by a reconfigurable DNA nanovault. Nat Commun. https://doi.org/10.1038/s41467-017-01072-8

115. Zhang Y, Hess H (2017) Toward rational design of high-efficiency enzyme cascades. ACS Catal 7:6018-6027

116. Rudiuk S, Venancio-Marques A, Baigl D (2012) Enhancement and modulation of enzymatic activity through higher-order structural changes of giant DNA-protein multibranch conjugates. Angew Chem Int Ed Engl 124:12866-12870

117. Lin J-L, Wheeldon I (2013) Kinetic enhancements in DNA-enzyme nanostructures mimic the sabatier principle. ACS Catal 3:560-564

118. Linko V, Eerikainen M, Kostiainen MA (2015) A modular DNA origami-based enzyme cascade nanoreactor. Chem Commun 51:5351-5354

119. Jonchhe S, Pandey S, Emura T, Hidaka K, Hossain MA, Shrestha P, Sugiyama H, Endo M, Mao H (2018) Decreased water activity in nanoconfinement contributes to the folding of G-quadruplex and i-motif structures. Proc Natl Acad Sci USA 115:9539-9544

120. Yaraghi NA, Kisailus D (2018) Biomimetic structural materials: inspiration from design and assembly. Annu Rev Phys Chem 69:23-57

121. Perham RN (2000) Swinging arms and swinging domains in multifunctional enzymes: catalytic machines for multistep reactions. Annu Rev Biochem 69:961-1004

122. Jones DD, Stott KM, Howard MJ, Perham RN (2000) Restricted motion of the lipoyl-lysine swinging arm in the pyruvate dehydrogenase complex of Escherichia coli. Biochemistry 39:8448-8459

123. Ke G, Liu M, Jiang S, Qi X, Yang YR, Wootten S, Zhang F, Zhu Z, Liu Y, Yang CJ, Yan H (2016) Directional regulation of enzyme pathways through the control of substrate channeling on a DNA origami scaffold. Angew Chem Int Ed Engl 55:7483-7486

124. Chen Y, Ke G, Ma Y, Zhu Z, Liu M, Liu Y, Yan H, Yang CJ (2018) A synthetic light-driven substrate channeling system for precise regulation of enzyme cascade activity based on DNA origami. J Am Chem Soc 140:8990-8996 
125. Yang YR, Fu J, Wootten S, Qi X, Liu M, Yan H, Liu Y (2018) 2D enzyme cascade network with efficient substrate channeling by swinging arms. Chembiochem 19:212-216

126. Piperberg G, Wilner OI, Yehezkeli O, Tel-Vered R, Willner I (2009) Control of bioelectrocatalytic transformations on DNA scaffolds. J Am Chem Soc 131:8724-8725

127. Tepper AWJW (2010) Electrical contacting of an assembly of pseudoazurin and nitrite reductase using DNA-directed immobilization. J Am Chem Soc 132:6550-6557

128. Ma K, Yehezkeli O, Domaille DW, Funke HH, Cha JN (2015) Enhanced hydrogen production from DNA-assembled Z-scheme TiO2-CdS photocatalyst systems. Angew Chem Int Ed Engl 54:11490-11494

129. Kopperger E, Pirzer T, Simmel FC (2015) Diffusive transport of molecular cargo tethered to a DNA origami platform. Nano Lett 15:2693-2699

130. Kopperger E, List J, Madhira S, Rothfischer F, Lamb DC, Simmel FC (2018) A self-assembled nanoscale robotic arm controlled by electric fields. Science 359:296-301

131. Kosuri P, Altheimer BD, Dai M, Yin P, Zhuang X (2019) Rotation tracking of genome-processing enzymes using DNA origami rotors. Nature 572:136-140

132. Ohmann A, Li C-Y, Maffeo C, Al Nahas K, Baumann KN, Göpfrich K, Yoo J, Keyser UF, Aksimentiev A (2018) A synthetic enzyme built from DNA flips 107 lipids per second in biological membranes. Nat Commun 9:2426. https://doi.org/10.1038/s41467-018-04821-5

133. Stein IH, Steinhauer C, Tinnefeld P (2011) Single-molecule four-color FRET visualizes energy-transfer paths on DNA origami. J Am Chem Soc 133:4193-4195

134. Dutta PK, Varghese R, Nangreave J, Lin S, Yan H, Liu Y (2011) DNA-directed artificial light-harvesting antenna. J Am Chem Soc 133:11985-11993

135. Dutta PK, Levenberg S, Loskutov A, Jun D, Saer R, Beatty JT, Lin S, Liu Y, Woodbury NW, Yan H (2014) A DNA-directed light-harvesting/reaction center system. J Am Chem Soc 136:16618-16625

136. Boulais É, Sawaya NPD, Veneziano R, Andreoni A, Banal JL, Kondo T, Mandal S, Lin S, SchlauCohen GS, Woodbury NW, Yan H, Aspuru-Guzik A, Bathe M (2017) Programmed coherent coupling in a synthetic DNA-based excitonic circuit. Nat Mater 17:159-166

137. Zhou X, Mandal S, Jiang S, Lin S, Yang J, Liu Y, Whitten DG, Woodbury NW, Yan H (2019) Efficient long-range, directional energy transfer through DNA-templated dye aggregates. J Am Chem Soc 141:8473-8481

138. Saghatelian A, Guckian KM, Thayer DA, Ghadiri MR (2003) DNA detection and signal amplification via an engineered allosteric enzyme. J Am Chem Soc 125:344-345

139. Gianneschi NC, Ghadiri MR (2007) Design of molecular logic devices based on a programmable DNA-regulated semisynthetic enzyme. Angew Chem Int Ed Engl 46:3955-3958

140. Mukherjee P, Leman LJ, Griffin JH, Ghadiri MR (2018) Design of a DNA-programmed plasminogen activator. J Am Chem Soc 140:15516-15524

141. Janssen BMG, Engelen W, Merkx M (2015) DNA-directed control of enzyme-inhibitor complex formation: a modular approach to reversibly switch enzyme activity. ACS Synth Biol 4:547-553

142. Kim Y, Phillips JA, Liu H, Kang H, Tan W (2009) Using photons to manipulate enzyme inhibition by an azobenzene-modified nucleic acid probe. Proc Natl Acad Sci USA 106:6489-6494

143. Xin L, Zhou C, Yang Z, Liu D (2013) Regulation of an enzyme cascade reaction by a DNA machine. Small 9:3088-3091

144. Hu Y, Wang F, Lu C-H, Girsh J, Golub E, Willner I (2014) Switchable enzyme/DNAzyme cascades by the reconfiguration of DNA nanostructures. Chem Eur J 20:16203-16209

145. Kou B, Chai Y, Yuan Y, Yuan R (2018) Dynamical regulation of enzyme cascade amplification by a regenerated DNA nanotweezer for ultrasensitive electrochemical DNA detection. Anal Chem 90:10701-10706

146. Xing C, Huang Y, Dai J, Zhong L, Wang H, Lin Y, Li J, Lu C-H, Yang H-H (2018) Spatial regulation of biomolecular interactions with a switchable trident-shaped DNA nanoactuator. ACS Appl Mater Interfaces 10:32579-32587

Publisher's Note Springer Nature remains neutral with regard to jurisdictional claims in published maps and institutional affiliations. 